\title{
The interrupted effect of autophagic flux and lysosomal function induced by graphene oxide in p62-dependent apoptosis of F98 cells
}

Chao Zhang ${ }^{1}$, Xiaoli Feng ${ }^{1}$, Longwen $\mathrm{He}^{1}$, Yaqing Zhang ${ }^{1}$ and Longquan Shao $12^{*}$

\begin{abstract}
Background: Graphene oxide (GO) nanoparticles (NPs) have been widely applied in various fields, especially in biomedical applications. Extensive studies have suggested that GO can pass through the blood-brain barrier (BBB) and induce abnormal autophagy and cytotoxicity in the central nervous system (CNS). However, the effect and specific mechanism of GO on astrocytes, the most abundant cells in the brain still has not been extensively investigated.

Results: In this study, we systematically explored the toxicity and mechanism of GO exposure in the rat astrogliomaderived F98 cell line using molecular biological techniques (immunofluorescence staining, flow cytometry and Western blot) at the subcellular level and the signaling pathway level. Cells exposed to GO exhibited decreased cell viability and increased lactate dehydrogenase (LDH) release in a concentration- and time-dependent manner. GO-induced autophagy was evidenced by transmission electron microscopy (TEM) and immunofluorescence staining. Western blots showed that LC3II/I and p62 were upregulated and PI3K/Akt/mTOR was downregulated. Detection of lysosomal acidity and cathepsin B activity assay indicated the impairment of lysosomal function. Annexin V-FITC-PI detection showed the occurrence of apoptosis after GO exposure. The decrease in mitochondrial membrane potential (MMP) with an accompanying upregulation of cleaved caspase-3 and Bax/Bcl-2 further suggested that endogenous signaling pathways were involved in GO-induced apoptosis.

Conclusion: The exposure of F98 cells to GO can elicit concentration- and time-dependent toxicological effects. Additionally, increased autophagic response can be triggered after $\mathrm{GO}$ treatment and that the blocking of autophagy flux plays a vital role in GO cytotoxicity, which was determined to be related to dysfunction of lysosomal degradation. Importantly, the abnormal accumulation of autophagic substrate p62 protein can induce capase-3-mediated apoptosis. Inhibition of abnormal accumulation of autophagic cargo could alleviate the occurrence of GO-induced apoptosis in F98 cells.
\end{abstract}

Keywords: Graphene oxide, Astrocyte, p62, Autophagy, Apoptosis

\section{Background}

Graphene oxide (GO) nanoparticles (NPs) have been widely used in biomedical fields due to their physical and chemical properties, which make them useful for

*Correspondence: shaolongquan@smu.edu.cn

${ }^{1}$ Stomatological Hospital, Southern Medical University (Guangdong Provincial Stomatological Hospital), Guangzhou 510280, China

Full list of author information is available at the end of the article applications in as drug delivery $[1,2]$, tumor photothermal therapy [3-5], bioimaging [6], tissue engineering [7, 8], antimicrobial agents $[9,10]$, biosensors [11-14]. At the same time, the risk of human contact has increased dramatically. A growing number of studies have reported that NPs can penetrate the blood-brain barrier (BBB) or enter brain tissues through nerve uptake, leading to potential dangers of the central nervous system (CNS) $[15,16]$. 
Astrocytes are the most abundant and widely distributed predominant cell group in the mammalian CNS, which performs critical functions vital to CNS physiology [17]. The formation of the BBB by astrocytes and endotheliocytes affects the passage of NPs into the CNS, which participates in the termination and recycling of neurotransmitters through the glutamateglutamine cycle and mediates the toxicity of neurons to NPs via the secretion of a series of cytokines and inflammatory cytokines [18, 19]. Therefore, studying the toxicity of astrocytes to NPs is an important part of the CNS toxicity to NPs [20]. Studies have shown that the uptake and internalization of titanium dioxide NPs can inhibit proliferation, induce the depolymerization of F-actin morphological changes, and lead to apoptosis in glial cells [21]. Exposure to silver NPs or zinc oxide NPs can induce oxidative stress and apoptosis of astrocytes [22, 23]. In addition, toxic effects on astrocytes are related to many neurodegenerative diseases, such as Alzheimer's disease, Parkinson's disease, Huntington's disease, ischemic stroke and epilepsy [24, 25]. Considering the crucial role of astrocytes and the great potential application of GO in the CNS, studying the effect and specific mechanism of GO on astrocytes is urgently required.

Autophagy, namely, macroautophagy in mammals, is a dynamic and multistep process that includes the formation of autophagosomes that engulf intracellular components, fusion between autophagosomes and lysosomes to form autolysosomes and, finally, degradation of the intracellular content in lysosomes [26]. The entire process of autophagy is also called autophagic flux. Microtubuleassociated protein 1 light chain 3 (LC3) is a marker of autophagy and has been confirmed to be involved in the entire process of autophagy. During autophagy, cytosolic LC3 (LC3I) hydrolyzes a small segment of polypeptide and converts to a phosphatidylethanolamine (PE)-conjugated form (LC3II), which functions as an integral membrane protein of autophagosomal membranes [27, 28]. The P62 protein is a ubiquitin-LC3-binding protein. In the late stage of the development of autophagy flux, p62 can mediate the formation of a complex between the ubiquitin substrate and LC3II and finally enter the autolysosome for degradation [29]. It was reported that after astrocytoma cells or primary astrocytes were exposed to amine-modified polystyrene NPs, apoptotic reactions and lysosomal acidification were observed [30]. In addition, PC12, a neuronal cell model, could induce apoptosis after exposure to GO by damaging autophagic flux [31]. Some NPs can cause autophagic flux perturbation and lysosomal dysfunction, leading to toxicological consequences [32]. However, it is not clear how GO affects the process and signaling pathways of autophagy in astrocytes, and the specific relationship between autophagy and apoptosis in the participation of GO remains unclear.

The purpose of this study was to investigate the effects of GO on cell viability, autophagy flux, lysosomal function and apoptosis in a rat astroglioma-derived F98 cell line. We used immunofluorescence staining, flow cytometry, Western blot and other molecular biological techniques to study the toxic mechanism at the subcellular level and the signaling pathway level. This study focuses on the toxicity of F98 cells to GO to fill the current gap regarding the effects of $\mathrm{GO}$ on astrocytes and to provide insight into the safe application of GO in the CNS.

\section{Methods}

\section{Reagents and antibodies}

GO nanosheet was obtained from Sigma-Aldrich (Shanghai, China). Dulbecco's modified Eagle's medium (DMEM), fetal bovine serum (FBS), streptomycin-penicillin and EDTA/trypsin were purchased from Thermo Fisher Scientific (Shanghai, China). An LDH-Cytotoxicity Assay Kit and a bicinchoninic acid (BCA) protein assay kit were from Beyotime (Nanjing, China). A cell counting kit-8 (CCK-8) test was purchased from Dojindo Molecular Technologies (Shanghai, China). Rapamycin and carbonyl cyanide 3-chlorophenylhydrazone; carbonyl cyanide 3-chlorophenylhydrazone; carbonyl cyanide m-chlorophenylhydrazone (CCCP) were from MCE (Shanghai, China). 2-(4-amidinophenyl)-6-indolecarbamidine dihydrochloride (DAPI) staining solution was obtained from Leagene Biotechnology (Beijing, China). 2.5\% glutaraldehyde for electron microscopy was obtained from Nacalai Tesque, INC (Japan). Lyso-Tracker Red and RIPA lysate buffer were obtained from Solarbio Life Sciences (Beijing, China). A human cathepsin B activity assay kit was purchased from Cusabio (Wuhan, China). An Annexin V-FITC-PI Apoptosis Kit and a Mitochondrial Membrane Potential (MMP) assay kit (JC-1) were obtained from KeyGEN BioTECH (Jiangsu, China). Rapamycin was purchased from HefeiAnqi Biotech Co., Ltd. (Hefei, China). Halt protease inhibitor and phosphatase inhibitor cocktail was from La Roche Ltd. (USA). Polyvinylidene fluoride (PVDF) membranes were purchased from R\&D Systems (USA). Primary antibodies, including antibodies for LC3I/II, p62, PI3K, Akt/pAkt, mTOR/p-mTOR, Bax, Bcl-2, caspase-3, and cleaved caspase-3, and horseradish peroxidase-conjugated (HRP) secondary antibodies were obtained from Abcam (Shanghai, China). Chemiluminescence substrate was obtained from EMD Millipore (Massachusetts, USA).

\section{Characterization of GO NPs}

The microstructure of GO was observed by scanning electron microscopy (SEM; Hitachi Ltd., Japan). 
Moreover, an atomic force microscope (AFM; Agilent Inc., USA) and a transmission electron microscope (TEM; Hitachi Ltd, Japan) for the original characterization of GO.

The functional groups and molecular structure of GO were determined by Raman spectroscopy (Renishaw, UK) and Fourier-transform infrared spectroscopy (FTIR) (Thermo Fisher Inc., USA). Basic chemical bonds and element content of GO were detected using X-ray photoelectron spectroscopy (XPS; Kratos, Japan).

$\mathrm{GO}$ nanosheets were sonicated using an ultrasonic processor (Biosafer, China) in pure water and cell culture medium to obtain uniformly dispersed suspension. The hydrodynamic size and zeta potentials of GO NPs in solution with uniform dispersion were measured using a Nano Zetasizer (Malvern Panalytical Ltd., England).

\section{Cell culture and preparation of $\mathrm{GO}$ suspension}

The rat astroglioma-derived F98 cell line (ATCC CRL2397) was purchased from Zhongqiao Xinzhou Co., Ltd. (Shanghai, China). After recovery from liquid nitrogen, F98 was cultured in DMEM containing 10\% FBS and 1\% streptomycin-penicillin and incubated in 95\% humidified air with $5 \%$ carbon dioxide at $37{ }^{\circ} \mathrm{C}$ to obtain a culture density of $1000 \mathrm{~cm}^{-2}$. During the culture process, the growth status and cellular morphology were observed using an ICX41 inverted biomicroscope (Sunny Optical Ltd, China). The cell culture medium was replaced every other day, and the average subculture time was 3-4 days.

A GO suspension with a concentration of $1 \mathrm{mg} / \mathrm{mL}$ was obtained in advance as the stock solution. After irradiation with ${ }^{60} \mathrm{Co}$, GO nanosheets were sonicated for $1 \mathrm{~h}$ 8 -times $(60 \mathrm{~Hz})$ by an ultrasonic processor. Before each administration, the storage solution of GO was diluted to different concentrations with complete medium supplemented with $10 \% \mathrm{FBS}$ and then ultrasonicated again for 30 min with a high-power ultrasonic crusher.

\section{Cell viability assay}

F98 cells were first inoculated in 96-well plates (Corning, USA) at a density of $5 \times 10^{3}$ cells/well and cultured in a $37^{\circ} \mathrm{C}$ incubator for $24 \mathrm{~h}$ prior to GO treatment. Then, the cells were exposed to fresh GO suspension at final concentrations of $10,20,40,50,60,80$, and $100 \mu \mathrm{g} / \mathrm{mL}$, while the control group was left untreated. After 6, 12 and $24 \mathrm{~h}$ of treatment, cell proliferation activity was evaluated by the CCK-8 test according to the supplier's protocol.

Cellular viability was further estimated by measuring the LDH release from injured cells. Briefly, the F98 cells were inoculated in 96-well plates $\left(5 \times 10^{3}\right.$ cells/ well) and cocultured with $\mathrm{GO}$ suspension at different concentrations $(20,40,50,60$ and $80 \mu \mathrm{g} / \mathrm{mL})$ for 6 and $24 \mathrm{~h}$. Wells containing only culture medium without cells (background blank control) and wells containing cells without GO (sample control) were used as negative controls. For the positive control, the maximum release of LDH was triggered by LDH release agent. After treatment, all supernatants were transferred to new 96-well plates and assessed by the LDH assay kit according to the supplier's protocol. At a wavelength of $490 \mathrm{~nm}$, the absorbance was analyzed using a full-spectrum microplate reader (Reagen, China).

On the basis of the CCK- 8 cell viability test, 40,60 and $80 \mu \mathrm{g} / \mathrm{mL}$ GO were selected, and rapamycin $(100 \mathrm{nM})$ was added for the same amount of time in the rescue experiment. Similarly, we measured cell viability by CCK-8 and LDH kits.

\section{SEM and TEM observation}

F98 cells were seeded on coverslips in 12-well plates $\left(5 \times 10^{4}\right.$ cells/well $)$ and cocultured with or without GO $(60 \mu \mathrm{g} / \mathrm{mL})$ for $24 \mathrm{~h}$. Thereafter, the cells were fasted overnight with $2.5 \%$ glutaraldehyde at $4{ }^{\circ} \mathrm{C}$ and washed with PBS. Subsequently, $1 \%$ osmium tetroxide was added to treat the cells at $4{ }^{\circ} \mathrm{C}$ for $1 \mathrm{~h}$. Finally, the cell coverslips were dehydrated with graded ethanol and gold sputtered. The cells were observed and photographed with a Hitachi S-3400N SEM.

For TEM observations, F98 cells were seeded in 6-well plates $\left(10^{5}\right.$ cells/well $)$ and then cocultured with or without GO $(60 \mu \mathrm{g} / \mathrm{mL})$ for $24 \mathrm{~h}$. The cells were washed with PBS, harvested with trypsin, centrifuged at $800 \mathrm{rpm}$ for $5 \mathrm{~min}$, and then fasted with $2.5 \%$ glutaraldehyde for $50 \mathrm{~min}$ at room temperature and for $3 \mathrm{~h}$ at $4{ }^{\circ} \mathrm{C}$. After dehydration with a graded series of ethanol, the cells were embedded with epoxy resin at $90{ }^{\circ} \mathrm{C}$ for 3 days. Finally, ultrathin sections $(70 \mathrm{~nm})$ were dyed with uranyl acetate-lead citrate and then observed and photographed by TEM.

\section{Detection of autophagy flux formation by immunofluorescence staining}

As previously described, F98 cells were seeded on glass coverslips and co-exposed with or without GO $(60 \mu \mathrm{g} /$ $\mathrm{mL}$ ) for $24 \mathrm{~h}$. Cells were also treated for the same amount of time with rapamycin $(100 \mathrm{nM})$ as the positive control. Thereafter, the cells were washed with PBS and fasted with $4 \%$ paraformaldehyde for $9 \mathrm{~min}$. Then, the cells were blocked for $1 \mathrm{~h}$, cocultured with the primary antibody at $4{ }^{\circ} \mathrm{C}$ overnight, and finally cocultured with the secondary antibody for $45 \mathrm{~min}$ at room temperature. The cells were dyed with DAPI staining solution at room temperature for $5 \mathrm{~min}$. Images were immediately observed by a BX63AFM microscope (Olympus, Japan). FITC and DAPI excitation/emission filters were selected for photography. 


\section{Detection of lysosomal acidity}

F98 cells were seeded and treated with 40, 60 and $80 \mu \mathrm{g} /$ $\mathrm{mL} \mathrm{GO}$ for $24 \mathrm{~h}$. After incubation, Lyso-Tracker Red was diluted to a working concentration with complete medium at a ratio of $1: 16,000$ and then cultured with cells at $37{ }^{\circ} \mathrm{C}$ for $1 \mathrm{~h}$. The cells were then washed with PBS. After removing the excess water with filter paper, the cells were inverted on a carrier plate, dripped with anti-fluorescence quenching tablet sealer, and observed by a BX63-AFM microscope. A FITC excitation/emission filter $(E x=495 \mathrm{~nm}, E m=515 \mathrm{~nm})$ was selected for photography. To quantitatively evaluate the strength of FITC fluorescence, cells were harvested with trypsin after the same treatment and then resuspended in PBS and instantly analyzed by flow cytometry (BD Biosciences, USA).

\section{Cathepsin B activity assay}

Cells were inoculated in $9 \mathrm{~cm}$ culture dishes at a density of $9 \times 10^{5}$ cells/dish. Similarly, F98 cells were treated with 40, 60 and $80 \mu \mathrm{g} / \mathrm{mL} \mathrm{GO}$ for $24 \mathrm{~h}$. The cells were subsequently washed with precooled PBS and harvested with trypsin. After two cycles of repeated freezing and thawing, the debris and cell fragments were centrifuged at $5000 \mathrm{rcf}$ for 5 min to collect the supernatant liquid, and cathepsin B activity was detected according to the supplier's protocol.

\section{Annexin V-FITC-PI assay}

F98 cells were plated on 6 -well plates $\left(2 \times 10^{5}\right.$ cells/well $)$ and treated with 40,60 and $80 \mu \mathrm{g} / \mathrm{mL}$ GO for $24 \mathrm{~h}$. In the rescue experiment, $60 \mu \mathrm{g} / \mathrm{mL} \mathrm{GO}$ and $60 \mu \mathrm{g} / \mathrm{mL}$ GO-100 nM rapamycin were included as the experimental groups. A blank control group and a rapamycin control group were also included. The old culture medium was abandoned, and the cells were washed with PBS. After that, the cells were harvested with trypsin and washed again with PBS. Then, $500 \mu \mathrm{L}$ of binding buffer was added to the resuspended cells, and $5 \mu \mathrm{L}$ of Annexin V-FITC and $5 \mu \mathrm{L}$ of propidium iodide (PI) were added in turn. After incubation in the dark at room temperature for $15 \mathrm{~min}$, the percentages of apoptotic cells were immediately detected by flow cytometry.

\section{Nuclear staining with DAPI}

Cells were cultured overnight on polylysine-coated dishes and then treated with $0,40,60$ and $80 \mu \mathrm{g} / \mathrm{mL}$ GO for $24 \mathrm{~h}$. Cells were treated separately with CCCP $(50 \mu \mathrm{M})$ for $30 \mathrm{~min}$ as a positive control. After incubation, the cells were harvested with trypsin, subsequently washed with PBS, fasted with $4 \%$ paraformaldehyde for $30 \mathrm{~min}$, and then labeled with DAPI staining solution for $10 \mathrm{~min}$. Changes in the nuclei were instantly observed by a BX63-AFM microscope. A DAPI excitation/emission filter $(E x=364 \mathrm{~nm}, E \mathrm{~m}=454 \mathrm{~nm})$ was selected for photography.

\section{Assessment of MMP}

Similarly, after $24 \mathrm{~h}$ of exposure to 40,60 and $80 \mu \mathrm{g} / \mathrm{mL}$ $\mathrm{GO}$, the cells were washed with PBS and incubated at $37{ }^{\circ} \mathrm{C}$ for $20 \mathrm{~min}$ with $5 \mu \mathrm{g} / \mathrm{mL} \mathrm{JC}-1$, a fluorescent carbocyanine dyestuff widely used to detect MMP. The cells were then washed and resuspended in JC-1 assay buffer $(1 \times)$, and red-green fluorescence was immediately detected by flow cytometry.

\section{Western blots}

After $24 \mathrm{~h}$ of treatment with 40, 60 and $80 \mu \mathrm{g} / \mathrm{mL}$ GO, the cells were washed with PBS, and RIPA lysate buffer containing protease inhibitor and phosphatase inhibitor cocktail were prepared to digest the cells. Cell granules and lysates were collected and centrifuged at 12,000 rpm for $30 \mathrm{~min}$. The supernatant was saved, and the total protein content was measured by a BCA protein assay kit. The newly extracted protein was used in 10\% SDS-PAGE (sodium dodecyl sulfate polyacrylamide gel electrophoresis) and then transferred to polyvinylidene fluoride (PVDF) membranes. Subsequently, the membranes were blocked for an hour and then incubated overnight with primary antibody at $4{ }^{\circ} \mathrm{C}$. The primary antibodies included LC3I/II, p62, PI3K, Akt/p-Akt, mTOR/pmTOR, Bax, Bcl-2, caspase-3, and cleaved caspase-3. Thereafter, the membranes were incubated with HRPconjugated secondary antibody at room temperature for an hour. GAPDH (glyceraldehyde-3-phosphate dehydrogenase) was designated as a loading control and showed no significant differences among groups. Finally, the protein bands were activated by chemiluminescent substrate and visualized by an enhanced chemiluminescence (CL) system (Tanon Science \& Technology Co., Ltd, China). The band intensities were quantified using ImageJ.

In the rescue experiment, $60 \mu \mathrm{g} / \mathrm{mL} \mathrm{GO}$ and $60 \mu \mathrm{g} /$ $\mathrm{mL}$ GO-100 $\mathrm{nM}$ rapamycin were included as the experimental groups. A blank control group and a rapamycin control group were also included. The primary antibodies were LC3I/II, p62, Bax, Bcl-2, caspase-3, and cleaved caspase-3, and the same operational steps were used as described above.

\section{Statistical analysis}

The results are expressed as the mean \pm standard deviation (SD) values of three independent experiments. All analyses were carried out using GraphPad Prism (USA) with unpaired Student's t-test or one-way ANOVA. The data were considered to be statistically significant when the probability $(\mathrm{p})<0.05$. 


\section{Results}

\section{Characterization of GO}

SEM showed that GO is a two-dimensional single-layer material with sharp and irregular edges and that the lateral size distribution varies from 50 to $800 \mathrm{~nm}$ (Fig. 1a). TEM further showed that large pieces of GO were flaky with a thin and wrinkled surface, easy to curl (Fig. 1b). The results of AFM (Fig. 1c) are consistent with SEM and
TEM, and the data analysis shows that the average thickness of GO used in this experiment was approximately $1.0 \mathrm{~nm}$.

Raman spectroscopy revealed three main peaks of GO: a D peak $\left(1368 \mathrm{~cm}^{-1}\right)$, a G peak $\left(1602 \mathrm{~cm}^{-1}\right)$ and $2 \mathrm{D}$ peaks at 2761.46 and $2769.17 \mathrm{~cm}^{-1}$ with symmetric line shapes (Fig. 1d). The $\mathrm{I}_{\mathrm{D}} / \mathrm{I}_{\mathrm{G}}$ strength ratio was 0.85 , which indicates that the molecular conformation a

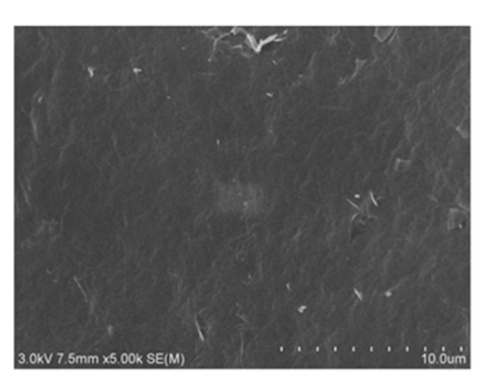

d

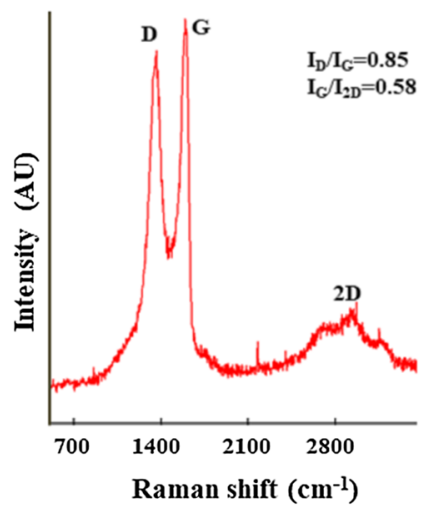

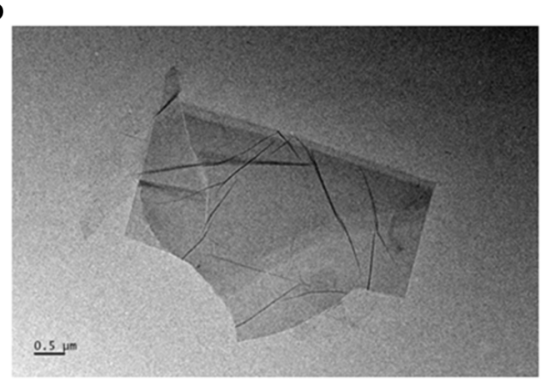

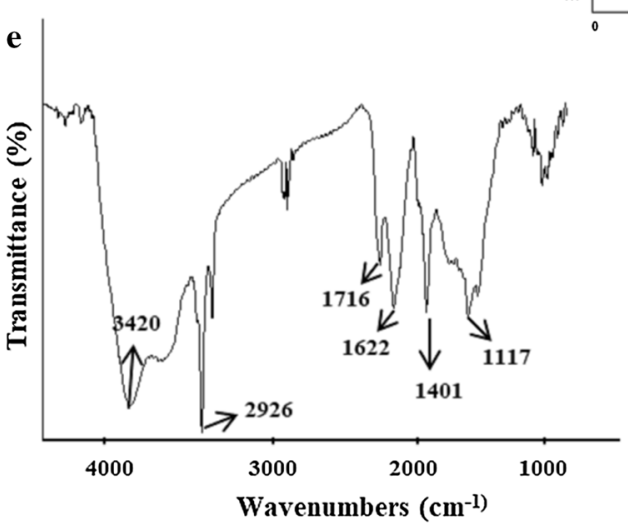

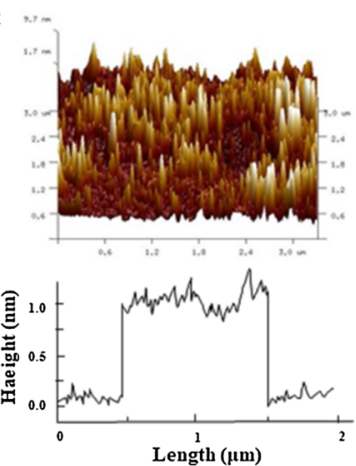

g

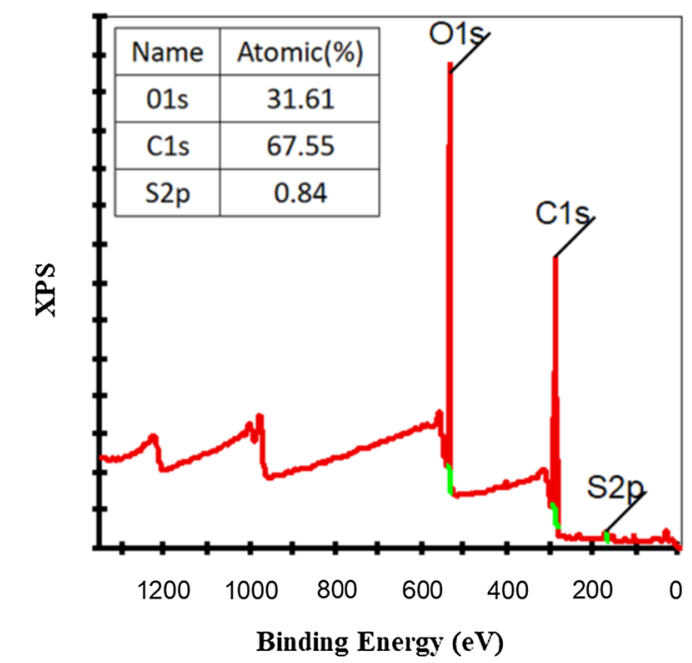

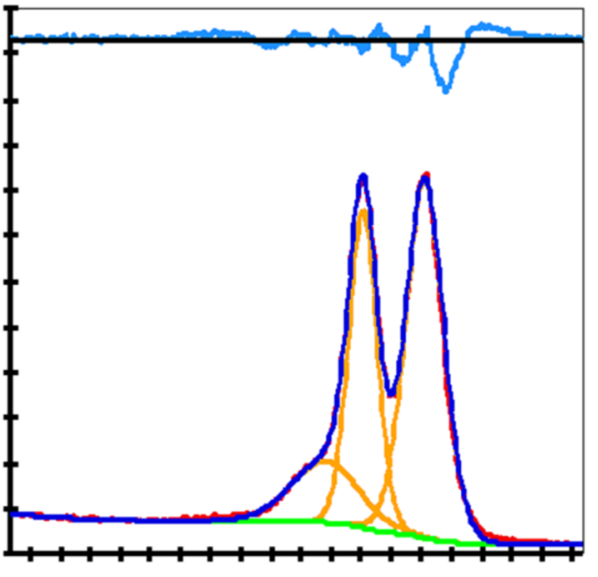

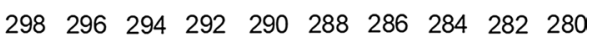

Fig. 1 Characterization of GO nanomaterials. a-c SEM, TEM and AFM images of GO; $\mathbf{d}$ identification of Raman spectroscopy; e identification of GO functional groups by FTIR; $\mathbf{f}, \mathbf{g}$ authentication of XPS to investigate the chemical composition of surfaces of GO 
of graphene changed after oxidation, i.e., via lattice distortion. The $\mathrm{I}_{\mathrm{G}} / \mathrm{I}_{2 \mathrm{D}}$ strength ratio was $0.58(<0.7)$, which confirms a single-layered graphene. The FTIR spectra show that the $3420 \mathrm{~cm}^{-1}$ and $1401 \mathrm{~cm}^{-1}$ positions correspond to the $\mathrm{O}-\mathrm{H}$ (hydroxyl) vibration absorption peak and deformation absorption peak, respectively (Fig. 1e). The $\mathrm{C}=\mathrm{O}$ (carboxyl) stretching vibration wave is located at $1716 \mathrm{~cm}^{-1}$. The peak for $\mathrm{C}=\mathrm{C}$ in the hybrid form of $\mathrm{sp}^{2}$ is located at $1622 \mathrm{~cm}^{-1}$, and the $\mathrm{C}-\mathrm{O}$ (alkoxy) stretching vibration wave is located at $1117 \mathrm{~cm}^{-1}$. Furthermore, the results of the full-spectrum analysis showed that the $\mathrm{C}, \mathrm{O}$ and $\mathrm{S}$ content in the GO samples was $67.55 \%, 31.61 \%$ and $0.84 \%$, which further confirmed the existence of oxygen groups in GO (Fig. 1f). XPS also revealed the basic chemical bonds of GO, including $\mathrm{C}-\mathrm{O}(287.1 \mathrm{eV})$, $\mathrm{C}=\mathrm{O} \quad(288.2 \mathrm{eV}), \mathrm{O}-\mathrm{C}=\mathrm{O} \quad(289.3 \mathrm{eV})$, and $\mathrm{C}=\mathrm{C}$ $(284.7 \mathrm{eV})$ (Fig. 1g).

\section{Concentration and exposure time-dependent cytotoxicity induced by GO}

The cell viability evaluated by the CCK- 8 assay showed a significant decrease at $80 \mu \mathrm{g} / \mathrm{mL}$ after $6 \mathrm{~h}$ of exposure compared with untreated cells (Fig. 2a). Nearly $50 \%$ of cell viability was observed after $12 \mathrm{~h}$ of treatment with $60 \mu \mathrm{g} / \mathrm{mL} \mathrm{GO}$, while a similar effect was observed after $24 \mathrm{~h}$ of exposure to $40 \mu \mathrm{g} / \mathrm{mL}$ GO. The results showed that GO had a significant concentration dependence on the proliferation toxicity of cells, which was consistent with the dose-dependent neurotoxicity of GO in rat pheochromocytoma PC12 cells [33]. We further studied the effect of increasing the exposure time of GO on cell viability. According to the known 50\% lethal dose (LD50) from CCK-8, three crucial concentrations of GO (40, $60,80 \mu \mathrm{g} / \mathrm{mL}$ ) were selected to observe the cytotoxicity after $6 \mathrm{~h}, 12 \mathrm{~h}$ and $24 \mathrm{~h}$, and then, the cell viability was detected. The results showed that the activity of cells exposed to GO for $24 \mathrm{~h}$ was markedly lower than that of cells treated with GO for $6 \mathrm{~h}$, which revealed significant a

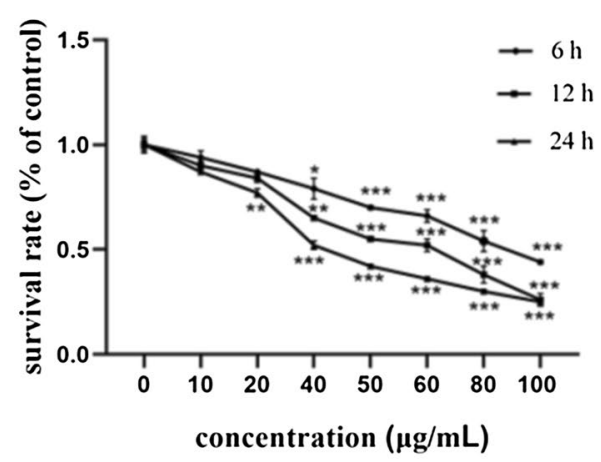

b

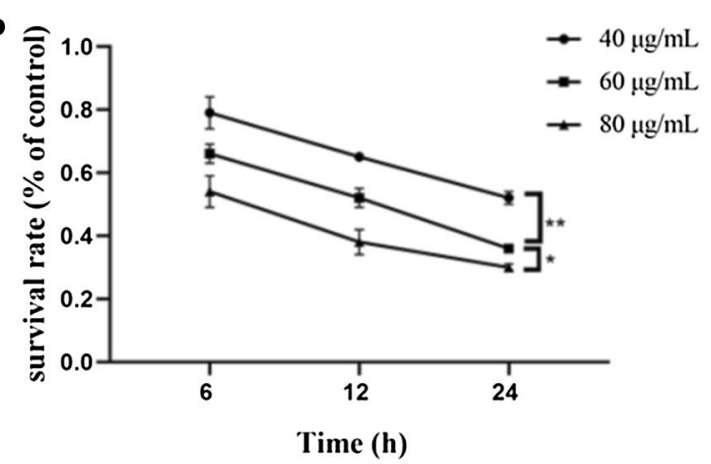

c

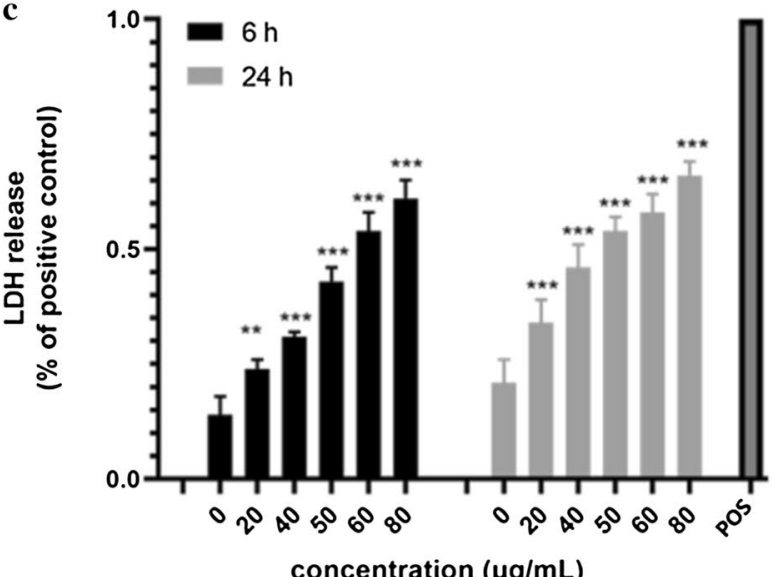

Fig. 2 Concentration- and time-dependent cytotoxicity of GO in F98 cells. a, b Cells were exposed to GO at different concentrations (10, 20, 40, 50, 60,80 and $100 \mu \mathrm{g} / \mathrm{mL}$ ) for different amounts of time ( $6 \mathrm{~h}, 12 \mathrm{~h}$ and $24 \mathrm{~h}$ ), and cell viability was assayed by CCK-8 assay. c Detection of LDH release in F98 cells treated with different concentrations of $\mathrm{GO}(20,40,50,60$ and $80 \mathrm{\mu g} / \mathrm{mL})$ for $6 \mathrm{~h}$ and $24 \mathrm{~h}$. The positive control (POS) corresponded to $100 \% \mathrm{LDH}$ release. All data are expressed as the mean \pm standard deviation (SD) of three independent experiments. ${ }^{*} p<0.05,{ }^{* *} p<0.01$ and ${ }^{* * *} p<0.001$ vs. the control group 
time-dependent toxicity (Fig. 2b). Interestingly, for $80 \mu \mathrm{g} /$ $\mathrm{mL}$ GO, the cell viability was $38 \%$ at $12 \mathrm{~h}$ and $30 \%$ at $24 \mathrm{~h}$, indicating that compared with prolonged culture time, the high concentration of GO had a stronger effect on cell viability.

LDH release is an important indicator of cell membrane damage and cytotoxicity. Compared with the positive control, the LDH level in untreated cells was $21 \%$, while the LDH level in cells exposed to GO at a concentration of $80 \mu \mathrm{g} / \mathrm{mL}$ was $66 \%$ after $24 \mathrm{~h}$ (Fig. 2c). Moreover, the release of LDH at $24 \mathrm{~h}$ was always higher than that at $6 \mathrm{~h}$, which was reflected in several concentrations. These results indicated that GO dose- and time-dependently increased the leakage of LDH.

\section{Cellular adhesion and uptake of $\mathrm{GO}$}

SEM observation showed that the cells in the control group were star-shaped with a smooth surface, clean background and no obvious impurities. After GO treatment, there was no significant change in the overall morphology of the cells, while there was a sheet of GO adherence on the surface and a large number of GO fragments in the background (Fig. 3a). The TEM results showed that the cell membrane exposed to GO was sunken inward, and lamellar GO was observed close to and even warped into the cell (Fig. 3b). SEM and TEM observations confirmed that $\mathrm{GO}$ interacts with the cell membrane to induce cytotoxicity.

\section{Autophagy is triggered following GO exposure}

TEM was used to further observe the distribution of GO in cells and its potential effect. The results showed that after GO treatment, extensive cytoplasmic vacuolization, including vacuolated mitochondria, could be observed in cells (Fig. 4a). In addition, GO is encapsulated by intracellular vesicles, such as autolysosomes and lipid vesicles. $\mathrm{GO}$ is a type of bad stimulation after internalization into cells, resulting in intracellular homeostasis imbalance and even autophagy induction. Studies have shown that autophagy can be triggered after GO treatment and that the blocking of autophagy flux plays a vital role in GO cytotoxicity [34, 35].

Autophagy is a unique cellular process for degrading long-lived proteins, damaged organelles and foreign bodies via the lysosomal degradation pathway. There are many molecules and proteins involved in autophagy, among which LC3 has been shown to be involved in the entire process of autophagy formation, and the accumulation of LC3II is a well-known sign of autophagy. To assay autophagic activation, LC3 was stained by single fluorescence, and the fluorescence intensity was observed under a fluorescence microscope, one of which was equivalent to an autophagosome [36]. The results showed no
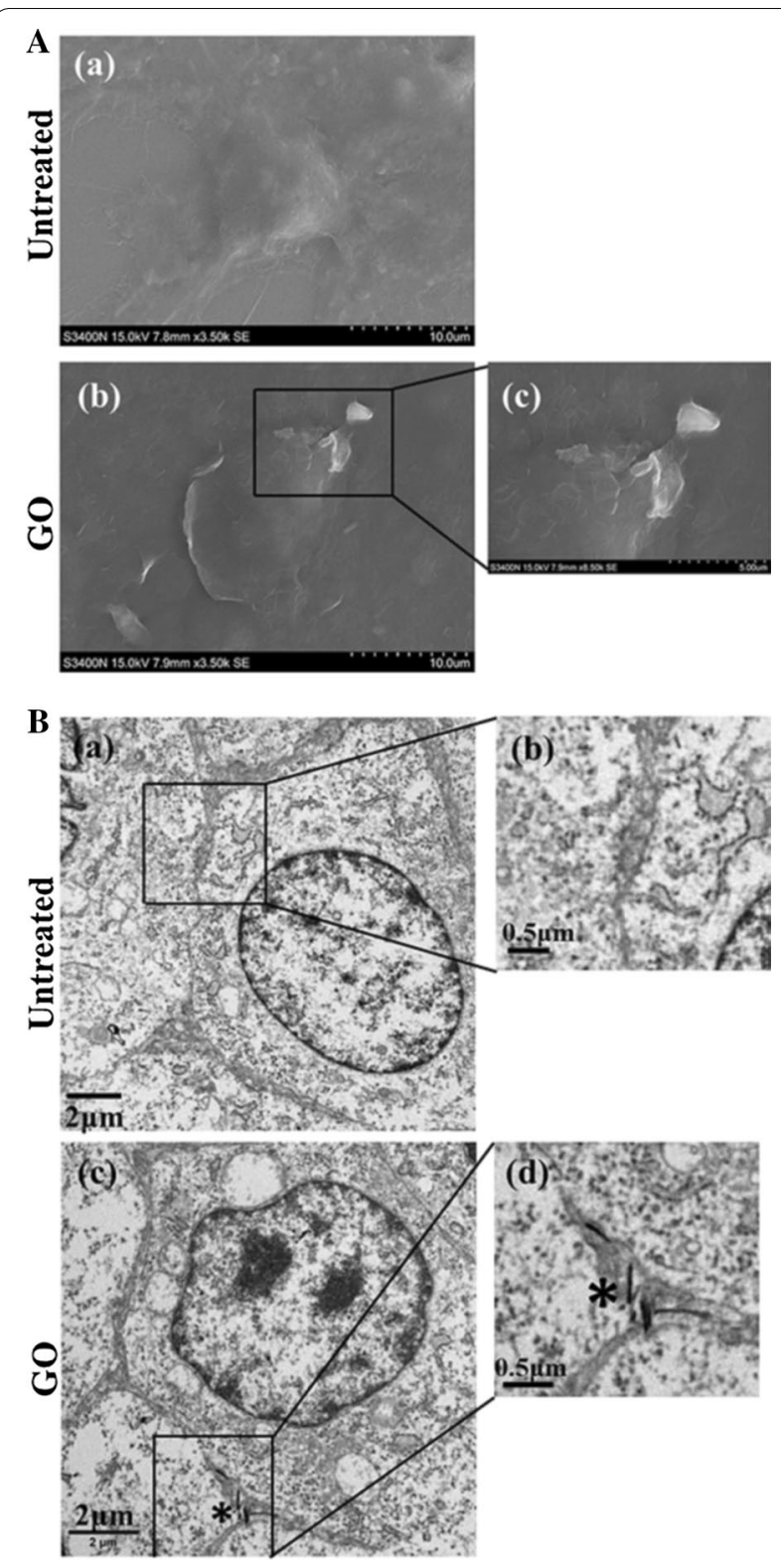

Fig. 3 The uptake and adhension of GO adhering to F98 cells. Identification of SEM (a) and TEM (b) imagines of F98 cells after treated with $\mathrm{GO}$ at the concentration of $60 \mu \mathrm{g} / \mathrm{mL}$ for $24 \mathrm{~h}$. The magnified images of the boxed area are shown on the right. *Indicates graphene oxide

obvious fluorescent spots in the cytoplasm of untreated cells (Fig. 4b). After treatment with $60 \mu \mathrm{g} / \mathrm{mL} \mathrm{GO}$ for $24 \mathrm{~h}$, a large number of fluorescent spots appeared in the cytoplasm. Rapamycin treatment, as a positive control, also induced a large number of autophagic fluorescent spots. The red fluorescent expression of cells in the positive control group was stronger than that in the GOtreated group, which showed that rapamycin enhanced 
autophagy [37]. The fluorescence microscopy results further confirmed that GO triggered autophagy in F98 cells, which was consistent with the TEM results.

The Western blotting results (Fig. 4c) showed that after GO treatment for $24 \mathrm{~h}$, the ratio of LC3II/I was markedly upregulated (Fig. 4d), and the expression of p62 was also upregulated (Fig. 4e). It is worth noting that cells exposed to $80 \mu \mathrm{g} / \mathrm{mL}$ GO exhibited more obvious upregulation than those exposed to $60 \mu \mathrm{g} / \mathrm{mL}$ and $40 \mu \mathrm{g} / \mathrm{mL}$ GO. With increasing GO concentration, LC3II/I and p62 expression increased more significantly compared with the control group, indicating that GO acts on F98 cells in a dose-dependent manner.

The expression of PI3K/Akt/mTOR, a main upstream signaling pathway of autophagy, was further evaluated by Western blot analysis. The results (Fig. 4f) showed that PI3K (Fig. 4g), p-Akt (Fig. 4h) and p-mTOR (Fig. 4i) were downregulated after $24 \mathrm{~h}$ of GO treatment, indicating that PI3K/Akt/mTOR signaling pathway function was inhibited during GO-induced autophagy. In addition, analysis of the protein band densities showed that higher GO dosages corresponded to more significant decreases in protein expression level, with a certain concentration dependence.

\section{$\mathrm{GO}$ induced lysosomal dysfunction in $\mathrm{F98}$ cells}

Lyso-Tracker Red is a type of lysosomal red fluorescent probe with weak alkaline labeling that can selectively stay in slightly acidic lysosomes, thus allowing lysosomal-specific staining. The fluorescence intensity increased under acidic conditions and decreased under alkaline conditions. Fluorescence microscopy showed that there was a large amount of red fluorescent spots in the cytoplasm of untreated cells, while the fluorescence density was significantly decreased after exposure to GO (Fig. 5a). With increasing GO concentration, the intracellular fluorescence intensity decreased, and the red fluorescence was the weakest at $80 \mu \mathrm{g} / \mathrm{mL}$. The results suggest that GO also has a concentration-dependent effect on the acidity of lysosomes. Flow cytometry was performed to quantitatively analyze the red fluorescence intensity (Fig. 5b, c). The results showed that the cells in the control group exhibited the highest fluorescence strength. With the increase in GO dosage, the fluorescence intensity of cells decreased, and the curve gradually shifted to the left, which further suggested that GO affected the acidity of the lysosomal cavity, resulting in a certain degree of alkalization in a concentration-dependent manner. The results of the cathepsin B activity test revealed that cathepsin B activity was obviously lower in cells exposed to $80 \mu \mathrm{g} / \mathrm{mL} \mathrm{GO}$ than in untreated cells (Fig. $5 \mathrm{~d}$ ). With the increase in GO concentration from 40 to $80 \mu \mathrm{g} / \mathrm{mL}$, cathepsin B activity decreased in a concentration-dependent manner.

\section{GO induced apoptosis in F98 cells}

Annexin V-FITC-PI double staining (Fig. 6a) showed that compared with untreated cells, the early apoptotic rate (Fig. 6b) and total apoptotic rate (Fig. 6c) of cells exposed to $80 \mu \mathrm{g} / \mathrm{mL}$ GO were $10.3 \%$ and $16.9 \%$, respectively, which were higher than those exposed to $60 \mu \mathrm{g} /$ $\mathrm{mL}$ and $40 \mu \mathrm{g} / \mathrm{mL} \mathrm{GO}$, indicating that GO caused dosedependent apoptosis. DAPI staining was also used to observe changes in the nuclei during apoptosis (Fig. 6d). Fluorescence microscopy showed that the nuclei of the control group were uniformly colored and the fluorescence intensity was darker. The CCCP treatment group, as a positive control group, exhibited apoptotic cells with obviously enhanced fluorescent spots or plaques in the nuclei after staining. In the experimental group, with the increase in GO concentration from 40 to $80 \mu \mathrm{g} / \mathrm{mL}$, the chromatic brightness of the nuclei increased $[38,39]$, and the fluorescence intensity inside the nuclei was uneven, with strong bright spots. The MMP detection kit is an ideal fluorescence probe that is extensively used to assay early cell apoptosis using the cationic fluorescent indicator JC-1. Red fluorescence can be produced when the MMP is high, and green fluorescence can be produced when the MMP is low. The red/green ratio can be generally used to assess the degree of mitochondrial depolarization. In this study, compared with control cells, the MMP assay showed that the red/green fluorescence ratio decreased significantly in GO-treated cells, and higher GO concentrations led to a more obviously decreased ratio (Fig. 6e, f). Studies have shown that MMP destruction is one of the earliest events in the process of cell

\footnotetext{
(See figure on next page.)

Fig. 4 Go triggers autophagy in F98 cells. a Identification of TEM imagines of F98 cells after treated with GO at the concentration of $60 \mu \mathrm{g} / \mathrm{mL}$ for $24 \mathrm{~h}$. Black arrowhead and black arrow indicate autophagosome and mitochondria, respectively. Black pentagon indicates initial autophagic vacuoles (AVi), containing a mitochondrion, endoplasmic reticulum membranes and ribosomes. Autophagic vacuoles (white arrowhead), mitochondria swelling and cristae vague (white arrows) as well as GO materials (*) were denoted; b F98 cells were treated with $60 \mu \mathrm{\mu g} / \mathrm{mL}$ GO for $24 \mathrm{~h}$. In addition, autophagy activator rapamycin ( $8 \mathrm{nM})$ was added for the same time as a positive control. The imagines of LC3 fluorescent labeling were captured under a fluorescence microscope; c-e the expression of P62 and LC3 II/I in F98 cells after treating with $40,60 \mathrm{and} 80 \mathrm{\mu g} / \mathrm{mL} \mathrm{GO} \mathrm{for}$ $24 \mathrm{~h} ; \mathbf{f}-\mathbf{i}$ The expression of PI3K, Akt/p-Akt and mTOR/p-mTOR in F98 cells after exposing to 40, 60 and $80 \mu \mathrm{g} / \mathrm{mL}$ GO for $24 \mathrm{~h}$. All datas expressed as mean $\pm S D$ in three independent experiment results. ${ }^{*} p<0.05,{ }^{* *} p<0.01$ and ${ }^{* *} p<0.001$ vs. control group
} 

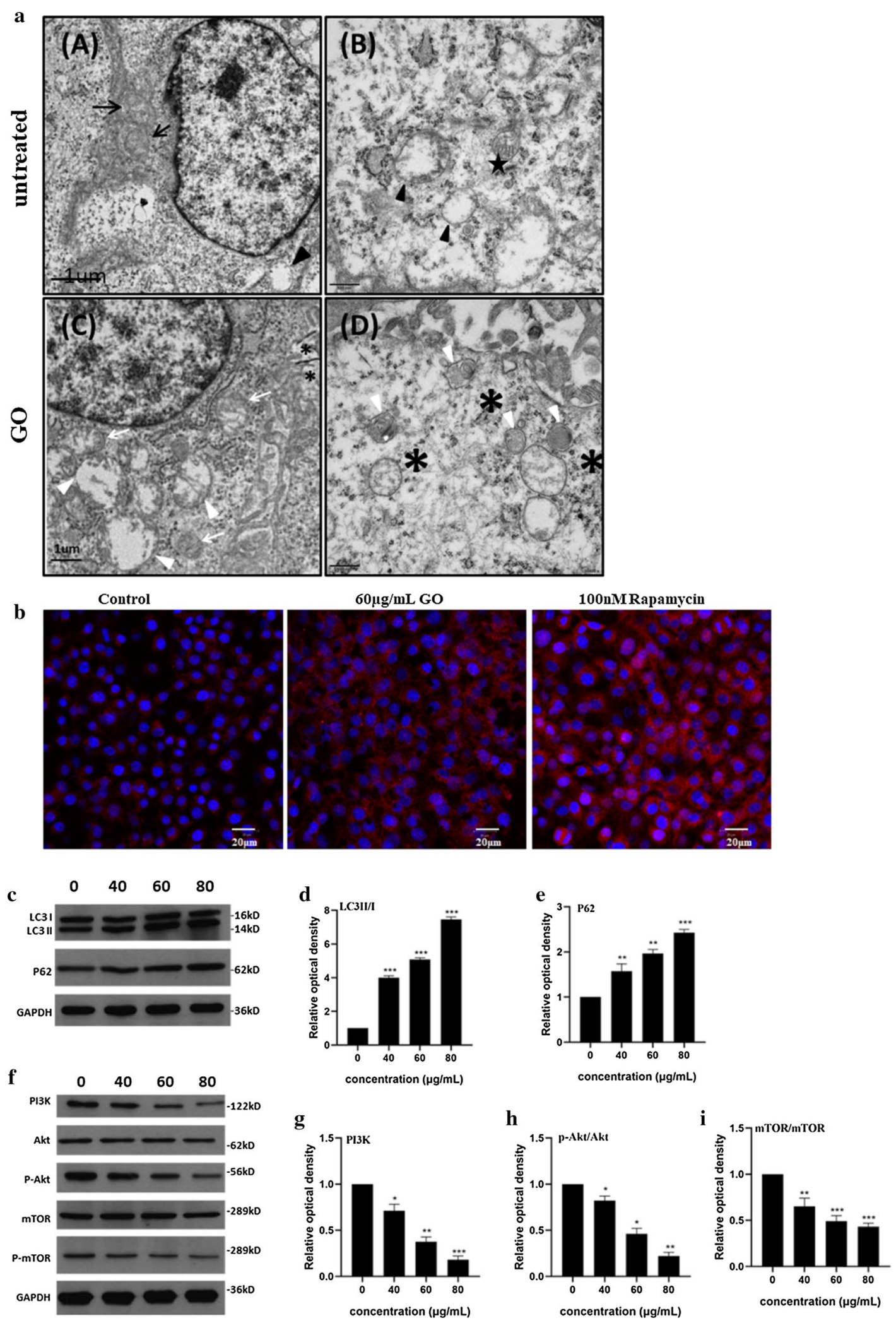


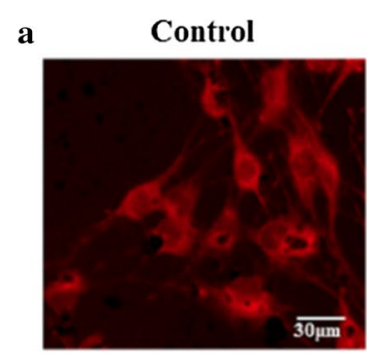

40X

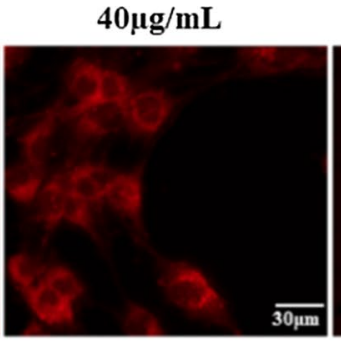

$40 X$
$60 \mu \mathrm{g} / \mathrm{mL}$

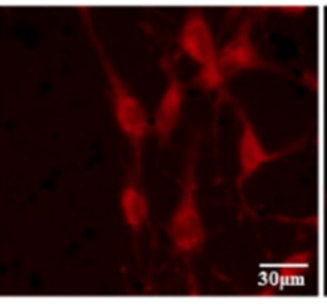

40X
$80 \mu \mathrm{g} / \mathrm{mL}$

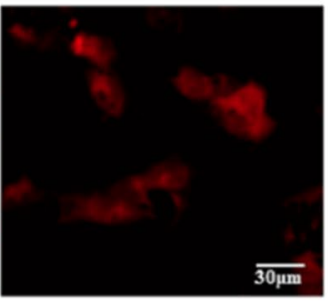

40X b

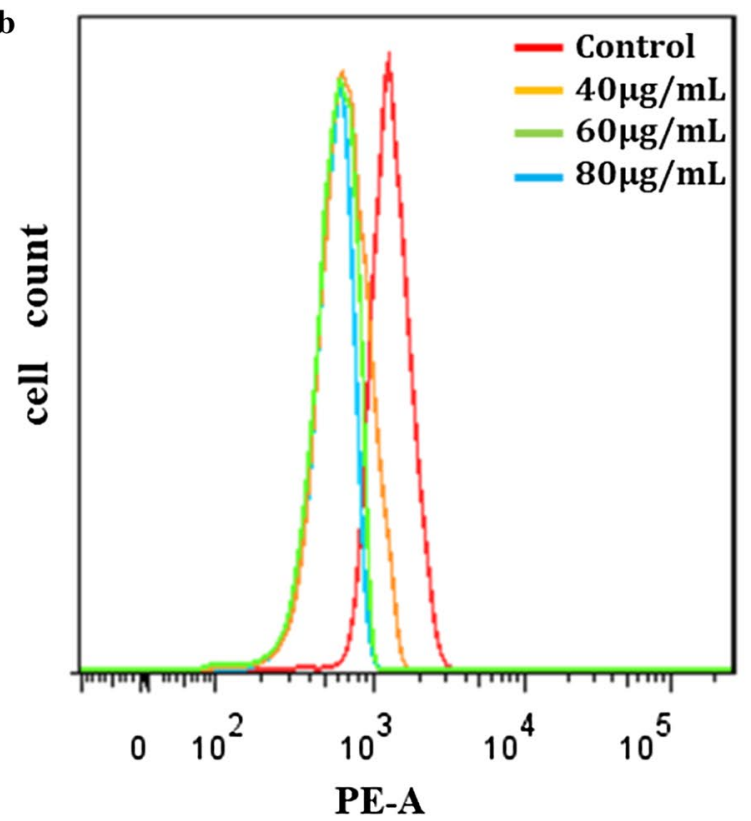

c

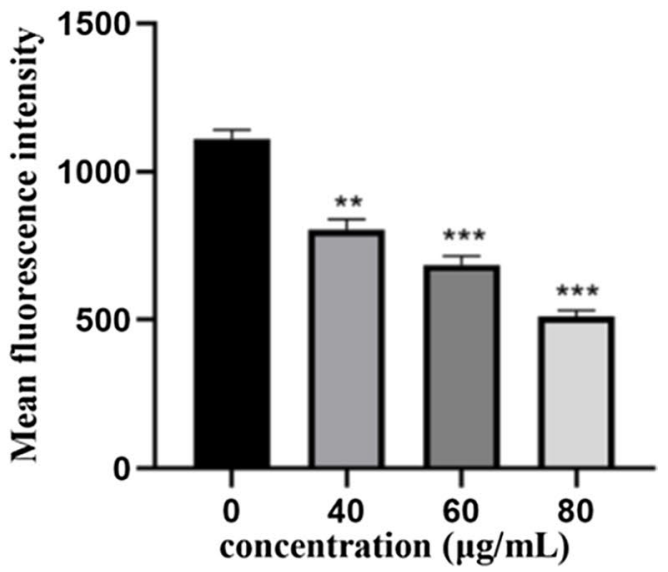

d

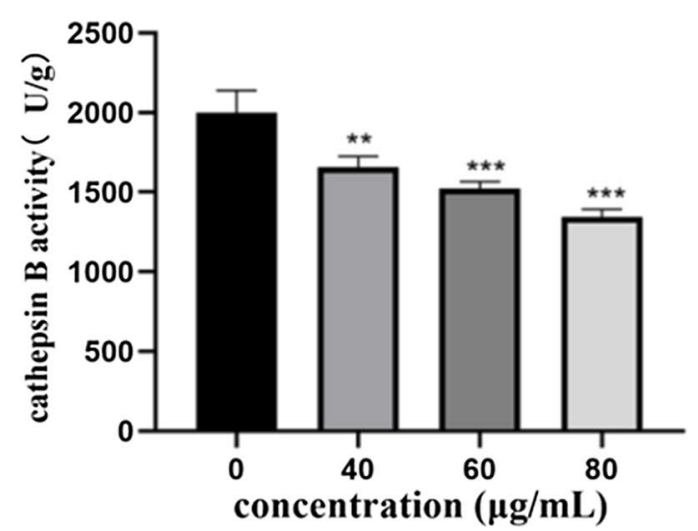

Fig. 5 GO induced lysosomal dysfunction in F98 cells. a F98 cells were exposed to 40,60 and $80 \mu \mathrm{g} / \mathrm{mL}$ GO for 24 h, and then incubated with 1 umol/L Lyso-Tracker Red. Representative imagines were photographed under a fluorescent microscope. b, c Flow cytometry was used to further detect Lyso-Tracker Red test for quantitative analysis of fluorescence images. $\mathbf{d}$ Determination of cathepsin B activity in F98 cells treated with 40 , 60 and $80 \mu \mathrm{g} / \mathrm{mL}$ GO for $24 \mathrm{~h}$. All datas expressed as mean \pm SD in three independent experiment results. ${ }^{*} p<0.05,{ }^{* *} p<0.01$ and ${ }^{* * *} p<0.001$ vs. control group 

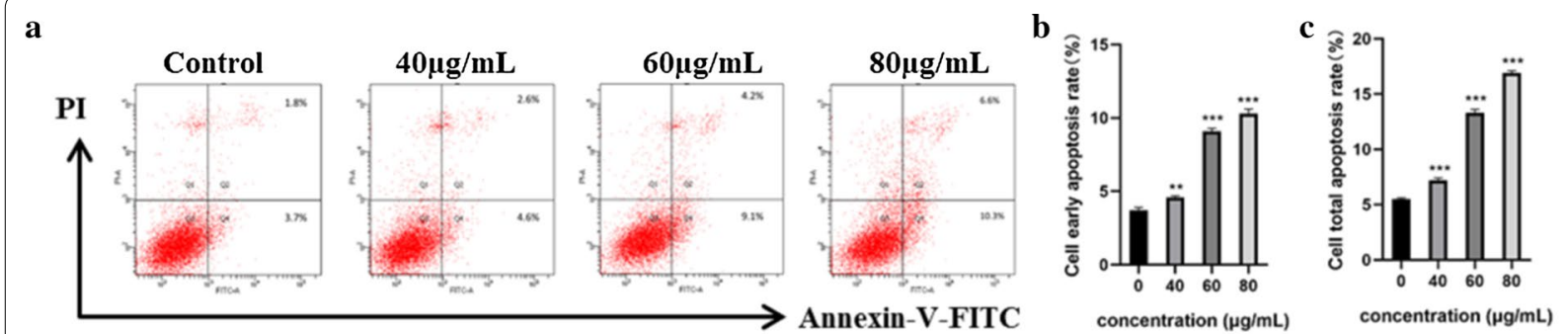

d

Control

$40 \mu \mathrm{g} / \mathrm{mL}$

$60 \mu \mathrm{g} / \mathrm{mL}$

$80 \mu \mathrm{g} / \mathrm{mL}$

CCCP
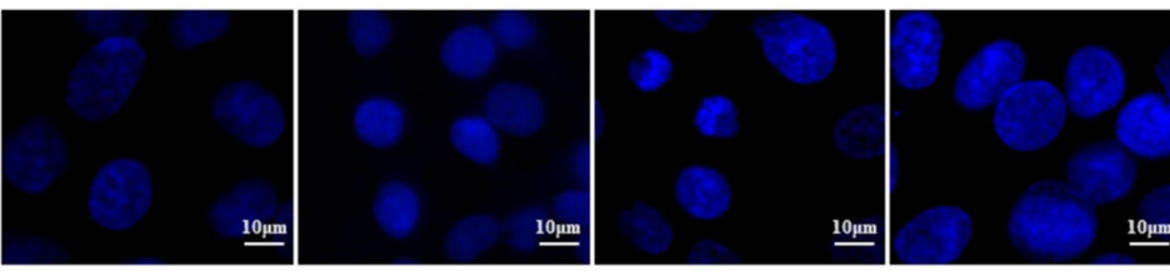

$40 X$

$40 X$

$40 \mathrm{X}$

$40 \mathrm{X}$

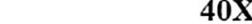

e
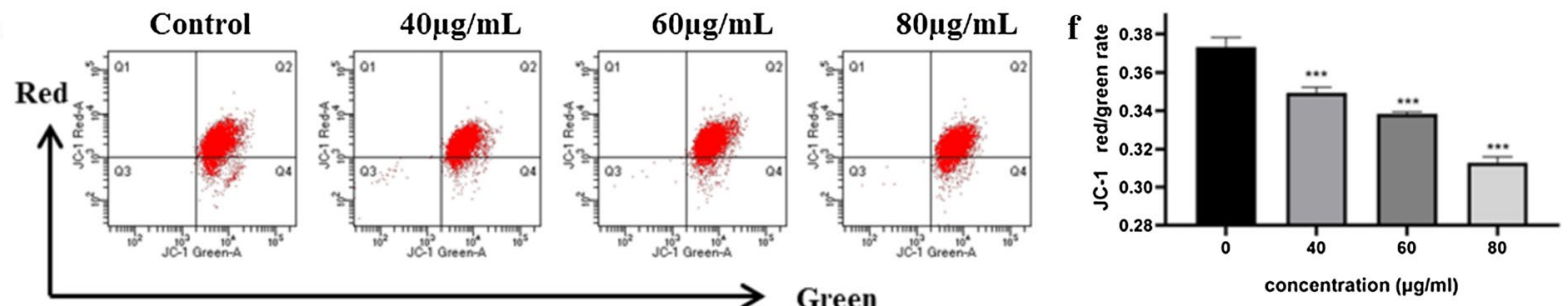

g
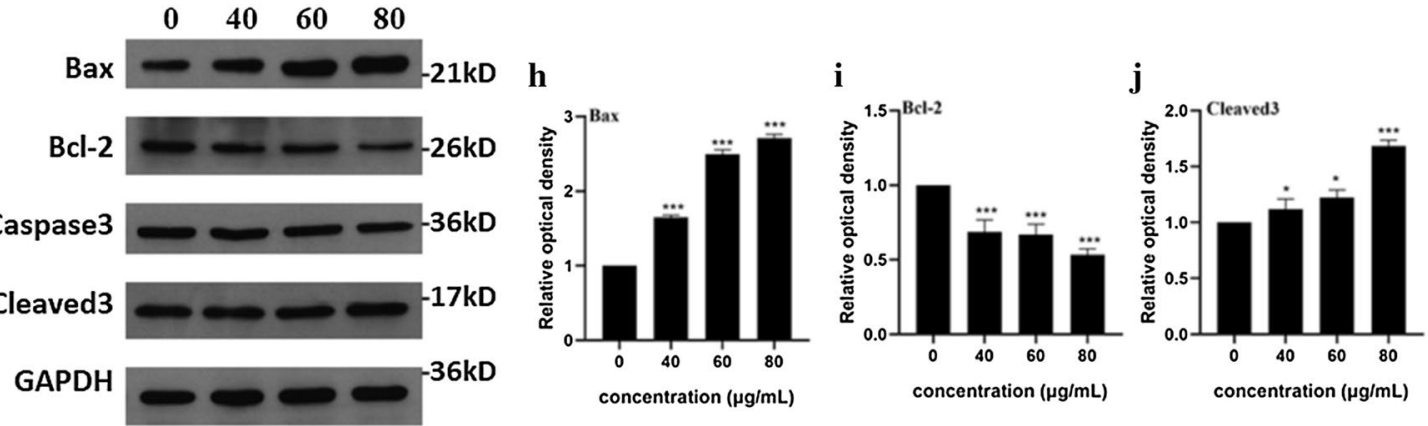

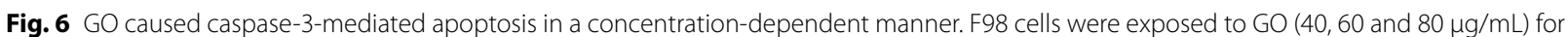
$24 \mathrm{~h}$. a-c The apoptosis was detected by AnnexinV-FITC-PI Apoptosis Kit. The early apoptosis rate (Q4) were located in the right lower quadrant and the total apoptosis rate $(\mathrm{Q} 2+\mathrm{Q} 4)$ are the sum of the right upper and the right lower quadrants. The column below shows the quantification of early and total apoptosis rates. $\mathbf{d}$ Before DAPI staining, CCCP, a kind of apoptosis inducer, was added as positive control to compare the changes of nucleus; $\mathbf{e}, \mathbf{f} \mathrm{GO}$-exposed cells were dyed with a fluorescent carbocyanine dyestuff JC-1 to investigate the effects of GO on MMP by detecting the ratio of red and green fluorescence in flow cytometry. $\mathbf{g}$ The expression of Bax (h), Bcl-2 (i), cleaved 3 (j) in GO-exposed cells were identified by western blots. The column on the right showed the quantification of gray-scale value of straps through Imagine J analysis. All datas expressed as mean $\pm S D$ in three independent experiment results. ${ }^{*} p<0.05,{ }^{* *} p<0.01$ and ${ }^{* * *} p<0.001$ vs. control group

apoptosis cascade reactions. Once MMP destruction occurs, apoptosis is irreversible [40]. The results showed that GO could reduce the red/green fluorescence ratio in a dose-dependent manner, which indicated that a loss of MMP and GO-induced concentration-dependent apoptosis occurred in F98 cells.
Western blots were used to observe the changes in related signaling pathways in the process of apoptosis. The results (Fig. 6g) showed that the proapoptotic proteins Bax (Fig. 6h) and cleaved caspase-3 (Fig. 6j) were upregulated and that the anti-apoptotic protein Bcl-2 (Fig. 6i) was downregulated after GO treatment in a 
concentration-dependent manner. Statistical analysis of the density of bands showed that the changes in histone levels in GO-treated cells were extensively different from those in untreated cells. Bax and $\mathrm{Bcl}-2$ proteins are mainly located upstream of irreversible cell damage and play a role at the mitochondrial level. Thus, we suggested that GO can induce caspase-3-mediated apoptosis in F98 cells by endogenous signaling pathways.

\section{Discussion}

It is noteworthy that the initial particle size of NPs often does not represent the real situation of their biomedical application. Compared with macromaterials, which are on the order of microns, nanomaterials belong to typical mesoscopic systems that have special effects, such as quantum size effects, surface and boundary effects, small-size effects and macroscopic quantum tunneling effects, and therefore, they more easily agglomerate when dispersed in solution. The average hydrodynamic size and zeta potential of GO detected by dynamic light scattering in pure water and cell culture medium are exhibited in Table 1 . The hydrodynamic size in the cell medium was higher than that in pure water. A possible reason is that GO can combine with proteins, antibiotic, and other biomolecules in biological fluids leading to the formation of "nanoparticle-protein corona" [41]. Even though FBS protein in cell culture medium can slightly improve the dispersion stability of GO $[42,43]$, GO showed to be very stable in pure water, indicating $\mathrm{GO}$ was more stable in pure water than in culture medium and less likely to cause aggregation. The GO in pure water exhibited a negative charge $(-29.66 \pm 0.79 \mathrm{mV})$, while the GO in complete culture medium showed a decreased negative charge of $-11.90 \pm 1.06 \mathrm{mV}$. The results also indicated that GO is more stable in pure water. It is worth noting that before DLS characterization of GO, adequately ultrasonic treatment is extremely important to get a uniform suspension of GO.

In this study, we investigated the cell viability of F98 cells exposed to different concentrations of GO by CCK- 8 detection and LDH test, whose result showed the concentration- and time-dependent cytotoxicity. Research reported that GO in a low concentration of $10 \mu \mathrm{g} / \mathrm{mL}$ upregulates the homeostatic functions of primary astrocytes

Table 1 Zeta potential and hydrodynamic diameter of GO samples

\begin{tabular}{lll}
\hline GO samples & Hydrodynamic size $(\mathbf{n m})$ & Zeta potential $(\mathbf{m V})$ \\
\hline In distilled water & $409.18 \pm 10.80$ & $-29.66 \pm 0.79$ \\
In culture medium & $747.02 \pm 18.5$ & $-11.90 \pm 1.06$
\end{tabular}

Data are the mean $\pm S D$ of three independent experiments and modulates astrocyte-to-neuron communication without affecting viability [44]. It is expected that GO can cause cell death or increase cell viability depending on the cell line and the dosage $[45,46]$. Notably, the cell viability assays revealed that F98 cells exhibited greater sensitivity to the LDH kit than to CCK- 8 detection. As mentioned above, the material characterization by TEM showed that GO was flaky with sharp and irregular edges (Fig. 1b), which was helpful for penetrating the lipid bilayer and "inserting" into the cell. It has been reported that GO can influence the ultrastructure of the plasma membrane of different cells, resulting in a loss of plasma membrane integrity since various concentrations of GO dose-dependently increase the leakage of $\mathrm{LDH}[47,48]$. The sharp edge of the two-dimensional GO nanosheets can easily lead to abnormal cell membrane stretching and cytotoxicity. Similarly, GO caused concentrationand time-dependent cytotoxicity in cells due to damage to the plasma membrane, which may be relevant to the intense physical interaction between $\mathrm{GO}$ nanosheets and the phospholipid bilayer [49]. The surface of GO is also flexible and foldable, which gives it Tulle-like properties in biological medium, allowing it to easily accumulate or adhere to the cell membrane [50]. GO nanosheets adhere to and wrap around the cell membrane, can become inserted into the phospholipid bilayer, or interact at the cellular level to enter the cell [51]. SEM and TEM observations further confirmed that GO interacts with the cell membrane to induce cytotoxicity, which was consistent with the LDH test.

As clearly highlighted in previous studies, the possible toxic mechanisms of graphene-family nanomaterials include physical damage, ROS production leading to oxidative stress, mitochondrial damage, DNA damage, inflammatory response, apoptosis, autophagy and so on [52]. While some physicochemical properties and the toxicological effects of GO have been reported, the underlying toxicity and specific mechanisms of $\mathrm{GO}$ remain unclear and need to be further evaluated. In this study, the subsequent observation of autophagy using TEM and immunofluorescence staining assays revealed several interesting findings. First, the enhancement of fluorescence intensity may not necessarily represent the enhancement of autophagic activity but may also reflect hindrance of the autophagic lysosome degradation pathway [53]. It is well known that the transformation of LC3I into LC3II is a hallmark of autophagy. P62 protein is another autophagic marker protein besides LC3II/I. The expression level of p62 is often used to evaluate the degradation activity of autophagic lysosomes [54]. Accordingly, we further verified the expression of autophagy substrates of LC3 and p62 by Western blotting to assess the pathway of autophagic lysosome degradation. 
Combined with the results of cellular immunofluorescence and TEM, we suggest that GO activates autophagy and induces the transformation of LC3I to LC3II. At the same time, to a certain extent, GO impairs the degradation function of autophagy flux, resulting in a reduction in ubiquitination substrate degradation mediated by p62, which leads to the abnormal accumulation of $\mathrm{p} 62$ [55-57]. Studies have shown that GO has adverse effects on mouse peritoneal macrophages with autophagosome accumulation and the conversion of LC3-I to LC3-II. The degradation of the autophagic substrate $\mathrm{p} 62$ protein was also inhibited. Further analyses on lysosomes showed that the accumulation of GO in macrophage lysosomes led to the instability of lysosomal membrane, indicating reduced autophagic degradation [58]. These results of abnormal autophagy flux are consistent with our results. However, the specific signaling pathways involved in this process have not been discussed, and we designed further experiments to explore.

Autophagy is regulated by a variety of signaling pathways. Mammalian target of rapamycin (mTOR) is a relatively conservative protein kinase of the phosphatidylinositol 3-kinase (PtdIns3K)-related family. Many studies have suggested a leading status for mTOR in autophagy [53, 59, 60]. Phosphatidylinositide 3-kinases (PI3K) and serine/threonine kinase (Akt) are upstream of mTOR, which could lead to the deactivation of mTOR by phosphorylation and trigger autophagy. In this study, the expression of PI3K/Akt/mTOR, a main upstream signaling pathway of autophagy, was further studied by Western blot analysis, and the results suggested that GO-induced autophagy was activated by suppressing the PI3K/Akt/mTOR signaling pathway. Previous studies have shown that GO-activated autophagy does not involve the mTOR pathway but depends on activation of the PtdIns3K and MEK/ERK1/2 signaling pathways [61]. A recent study also suggested that downregulation of PI3K/Akt/mTOR signaling pathways leads to GOinduced autophagy [31].

Extensive studies have established that impairment of autophagy flux and lysosomal dysfunction are emerging mechanisms of NP cytotoxicity. For instance, graphite carbon nanofibers could impair autophagy flux via lysosomal dysfunction, which leads to autophagosome accumulation [56]. Zinc oxide NP-induced autophagic flux disorder and lysosomal malfunction were closely correlated with toxicity [62]. Accordingly, this study further examined whether the situation and function of lysosomes were impaired to explore the basis of autophagic dysfunction. The intraluminal $\mathrm{pH}$ value of lysosomes $(\mathrm{pH}=4.5-5.5)$ is one of the most important factors affecting lysosomal physiological function [63, 64]. Studies have shown that NPs can induce lysosome dysfunction by affecting acidity [65]. Therefore, it is necessary to monitor the $\mathrm{pH}$ of lysosomes for studying lysosome degradation function. Cathepsin $\mathrm{B}$, a cysteine proteolytic enzyme, is active in the $\mathrm{pH}$ range of 3.0-7.0, but it can be irreversibly inactivated under alkaline conditions, which plays an essential role in lysosomal degradation of substrates. The results of this study suggest that the alkalization of lysosomes can lead to a decrease in cathepsin B activity and dysfunction of autophagic flux, thus further blocking degradation of the autophagy substrate p62 and leading to its accumulation.

The main function of the lysosome is digestion; lysosomes not only participate in the development of autophagic flux but are also the most important digestive organ in cells. The normal function of lysosomes is very important for maintaining the stability of the intracellular environment, resisting harmful stimulation and renewing intracellular components. Damage to lysosomal function will have adverse effects on cell viability and even lead to apoptosis [63, 66, 67]. Previous studies have shown that graphene and GO can induce the loss of MMP and the increase of ROS, which trigger MAPKs- and TGF- $\beta$ related signaling pathways, and activate caspase- 3 in a mitochondrial dependent manner, thus initiating the execution of apoptosis [68,69]. In this study, multiple biochemical detection methods were used to observe the occurrence of apoptosis from many aspects after lysosomal dysfunction. Apoptosis is a type of programmed cell death. There are two major pathways involved in this process: the exogenous signaling pathway triggered by the death receptor and the endogenous signaling pathway initiated by mitochondria. There are intricate relationships between the two pathways that together regulate the apoptosis process of cells. Caspase, known as apoptosis protease, plays an irreplaceable role in both apoptosis pathways. It is well known that caspase- 3 is a vital terminal shear during apoptosis [70]. Cleaved caspase-3 can degrade many kinds of cell proteins and is responsible for the charge of the morphological changes and DNA breakage in the process of apoptosis. The $\mathrm{Bcl}-2$ gene enzyme e is the first to be found and confirmed to play a crucial role in monitoring apoptosis. Its expression products together constitute the Bcl-2 family. Some members of the Bcl-2 family, such as Bcl-2, show resistance to apoptosis, whereas others, such as Bax, show promotion of apoptosis [71, 72]. The results of this study indicated caspase-3 mediated apoptosis after GO exposure.

Through the above experiments, we suggest that GO could induce the blocking of autophagic flux through repairing the physiological function of lysosomes and even resulting in apoptosis after internalization into cells. Notably, blockade of autophagic flux leads to excessive accumulation of p62 protein. On the one hand, it causes 

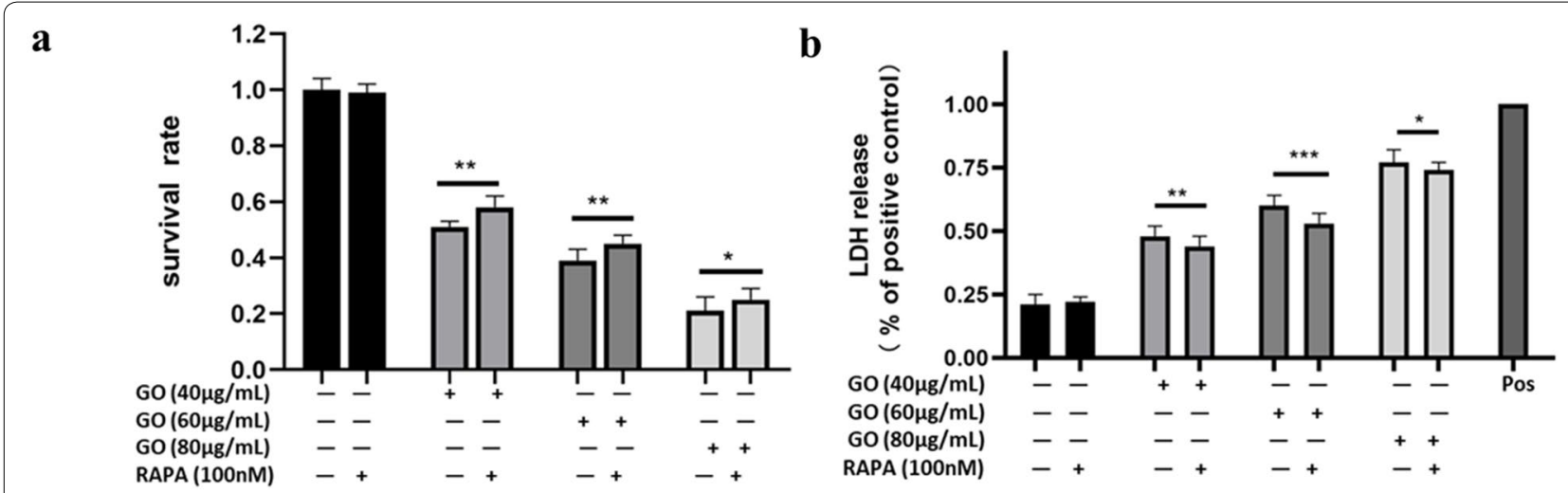

C

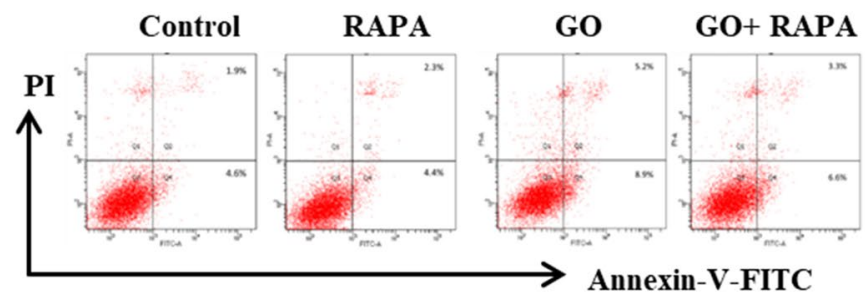

d
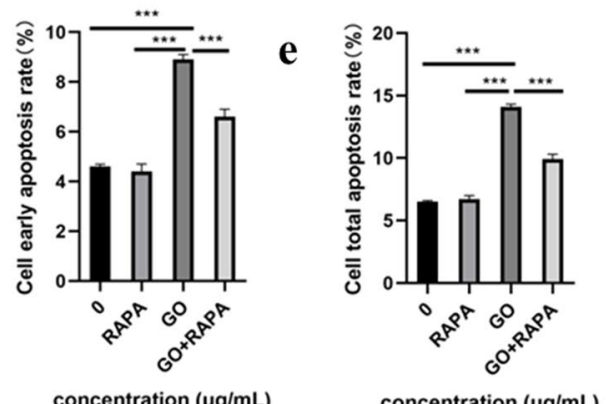

f $\mathrm{GO}(60 \mu \mathrm{g} / \mathrm{mL})--+$
$\operatorname{Rapa}(100 \mathrm{nM})-+$
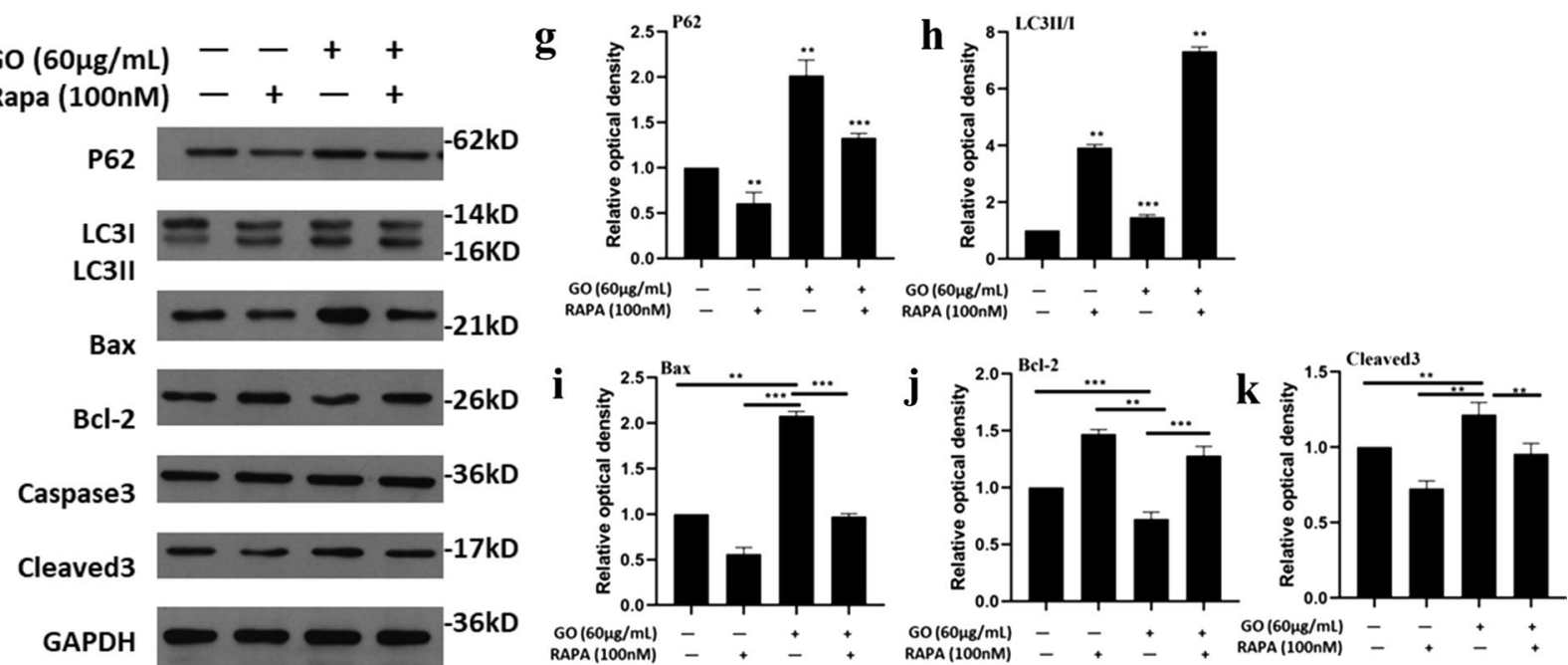

Fig. 7 Verification of P62-mediated cytotoxic response. a, b F98 Cells were exposed to GO $(40,60,80 \mu \mathrm{g} / \mathrm{mL})$ with or without treatment of rapamycin ( $8 \mathrm{nM}$ ) for $24 \mathrm{~h}$. The cell viability was analyzed using CCK-8 and LDH kits, respectively. c-e F98 cells were treated with $60 \mu \mathrm{g} / \mathrm{mL} \mathrm{GO}$ with or without treatment of rapamycin $(8 \mathrm{nM})$ for $24 \mathrm{~h}$ to investigate the cell apoptosis by Annexin V-FTIC-PI apoptosis kit. The column on the right exhibited the quantification of flow cytometry results. $\mathbf{f}$ Similarly, GO-treated cells were incubated with or without rapamycin for $24 \mathrm{~h}$. The expression of p62 (g), LC3II/I (h), Bax (i), BCl-2 (j), cleaved 3 ( $\mathbf{k})$ were detected by western blots. The column on the right showed the quantification of gray-scale value of straps through Imagine $J$ analysis. All datas expressed as mean \pm SD in three independent experiment results. ${ }^{*} p<0.05$, ${ }^{* *} p<0.01$ and ${ }^{* *} p<0.001$ vs. control group

lysosome overload, aggravates lysosome membrane damage and releases more hydrolases to cause cell damage. On the other hand, p62, as a cross-linking protein of the autophagy and apoptotic pathway, may also participate in the process of apoptosis [54, 73]. Autophagy is a complex stress process involving many steps and dozens of proteins. The regulation of different proteins in the autophagy process through drug intervention will have 
complex and variable effects on the autophagy process. Rapamycin, a classical autophagic activator, can effectively promote the development of autophagic flux by inhibiting the function of mTOR, which is widely used in autophagy research. As shown in Fig. 7a, treatment with $100 \mathrm{nM}$ rapamycin alone caused no significant decrease in cellular viability compared with the control group, indicating that rapamycin in this dose had good biocompatibility. At the same time, when cells were treated with GO in the presence of rapamycin, the GO-induced cell viability decline was significantly alleviated, and the salvage effect for different concentrations of GO treatment is shown. The LDH test results (Fig. 7b) are consistent with the CCK- 8 assay. Similarly, rapamycin could also alleviate GO-induced apoptosis according to the Annexin V-FITC-PI double staining test (Fig. 7c). Rapamycin combined with GO significantly reduced GO-induced apoptosis, including reducing the early apoptotic rate (Fig. 7d) and the total apoptotic rate (Fig. 7e), which can be reflected when the concentration of GO is 40,60 , and $80 \mu \mathrm{g} / \mathrm{mL}$. Statistical analysis also suggested that there was a marked divergence between the two groups. Western blots showed that the level of LC3 II/I was upregulated and the level of p62 was downregulated significantly compared with the control group (Fig. $7 \mathrm{f}-\mathrm{h}$ ).

These results suggest that rapamycin treatment alone could effectively promote the development of autophagic flux. In addition, when cells were treated with GO in the presence of rapamycin, the proapoptotic proteins Bax and cleaved caspase-3 were downregulated, while the anti-apoptotic protein $\mathrm{Bcl}-2$ was upregulated (Fig. $7 \mathrm{i}-\mathrm{k}$ ). These results suggest that rapamycin could promote the development of autophagic flux and alleviate the abnormal accumulation of p62 in GO-treated cells. Furthermore, rapamycin could increase the viability of cells and showed certain rescue effects against apoptosis. The abnormal accumulation of p62 plays an important role in GO-induced cytotoxicity in F98 cells, and alleviating the abnormal accumulation of p62 in F98 cells can alter GO-induced cytotoxicity.

\section{Conclusion}

In the present study, we reported the interaction of GO with the rat astroglioma-derived F98 cell line accompanied by interlink between autophagy, lysosomes and apoptosis. The results indicate that the exposure of F98 cells to GO can elicit concentration- and timedependent toxicological effects. GO-treated cells exhibited autophagy activation by inhibiting the PI3K/Akt/ mTOR signaling pathway. Simultaneously, GO can induce the dysfunction of lysosomes via alkalizing lysosomes and then block autophagic flux, resulting in the abnormal accumulation of autophagic substrate p62 protein. Abnormal accumulation of p62 protein can induce capase-3-mediated apoptosis. Rapamycin, an autophagy activator, can promote autophagic flux development and alleviate the occurrence of GO-induced cytotoxicity. This study sheds light on the lack of effect of GO on astrocytes and provides insights into the safe application of graphene-family NPs in the CNS. Moreover, it is clear that astrocytes exposed to $\mathrm{GO}$ can downregulate the PI3K/ Akt/mTOR signaling pathway to activate autophagy; however, the pathway of upregulated autophagy activation remains unclear, and further research is needed in the future.

\section{Abbreviations}

Akt: Serine/threonine kinase; AFM: Atomic force microscope; BBB: Blood-brain barrier; BCA: Bicinchoninic acid; CCCP: Carbonyl cyanide 3-chlorophenylhydrazone; carbonyl cyanide m-chlorophenylhydrazone; CCK-8: Cell counting kit-8; CNS: Central nervous system; DAPI: 2-(4-Amidinophenyl)-6-indolecarbamidine dihydrochloride; DMEM: Dulbecco's modified Eagle's medium; FBS: Fetal bovine serum; FTIR: Fourier-transform infrared spectroscopy; GAPDH: Glyceraldehyde-3-phosphate dehydrogenase; GO: Graphene oxide; HRP: Horseradish peroxidase-conjugated; LC3: Microtubule-associated protein 1 light chain 3; LC3I: Cytosolic LC3; LC3II: Phosphatidylethanolamine (PE)-conjugated form; LDH: Lactate dehydrogenase; MMP: Mitochondrial membrane potential; NPs: Nanoparticles; PI3K: Phosphatidylinositide 3-kinases; PVDF: Polyvinylidene fluoride; SEM: Scanning electron microscopy; SD: Standard deviation; TEM: Transmission electron microscopy; XPS: X-ray photoelectron spectroscopy.

\section{Acknowledgements}

Not applicable.

\section{Authors' contributions}

$C Z, L Q S$ and XLF designed the study. CZ was responsible for study coordination and acquisition of data on GO characterization and cell viability assays. XLF contributed to the acquisition of data on autophagy activation and lysosome dysfunction. YQZ was responsible for apoptosis detection and rescue experiments. ZC and XLF analyzed the data. LWH generated the figures and drafted the manuscript, which was critically revised by ZC and XLF. All authors corrected the manuscript. All authors read and approved the final manuscript.

\section{Funding}

This work funded by the National Natural Science Foundation of China (81801007), the Postdoctoral Science Foundation of China (2019M652980), the Natural Science Foundation of Guangdong Province (2018A030310442), and the Science and Cultivation Foundation of Stomatological Hospital of Southern Medical University (PY2018027).

Availability of data and materials

The datasets used and/or analyzed in the current study are available from the corresponding author on reasonable request.

Ethics approval and consent to participate Not applicable.

\section{Consent for publication}

Not applicable.

\section{Competing interests}

The authors declare that they have no competing interests.

\section{Author details}

${ }^{1}$ Stomatological Hospital, Southern Medical University (Guangdong Provincial Stomatological Hospital), Guangzhou 510280, China. ${ }^{2}$ Guangdong Provincial Key Laboratory of Construction and Detection in Tissue Engineering, Guangzhou 510515, China. 
Received: 21 January 2020 Accepted: 6 March 2020

Published online: 18 March 2020

\section{References}

1. Mahajan CR, Joshi LB, Varma U, Naik JB, Chaudhari VR, Mishra S. Sustainable drug delivery of famotidine using chitosan-functionalized graphene oxide as nanocarrier. Glob Chall. 2019;3(10):1900002.

2. Dowaidar M, Abdelhamid HN, Hällbrink M, Zou X, Langel Ü. Graphene oxide nanosheets in complex with cell penetrating peptides for oligonucleotides delivery. Biochim Biophys Acta Gen Subj. 2017;1861(9):2334-411.

3. Zhang B, Yu Q, Zhang YM, Liu Y. Two-dimensional supramolecular assemblies based on beta-cyclodextrin-grafted graphene oxide for mitochondrial dysfunction and photothermal therapy. Chem Commun. 2019;55(81):12200-3.

4. Gai LX, Wang WQ, Wu X, Su XJ, Yang FC. NIR absorbing reduced graphene oxide for photothermal radiotherapy for treatment of esophageal cancer. J Photochem Photobiol B. 2019;194:188-93.

5. Zhang H, Li Y, Pan Z, et al. Multifunctional nanosystem based on graphene oxide for synergistic multistage tumor-targeting and combined chemo-photothermal therapy. Mol Pharm. 2019;16(5):1982-98.

6. Chawda N, Basu M, Majumdar D, Poddar R, Mahapatra SK, Banerjee I. Engineering of gadolinium-decorated graphene oxide nanosheets for multimodal bioimaging and drug delivery. ACS Omega. 2019;4(7):12470-9.

7. Lee J, Manoharan V, Cheung L, et al. Nanoparticle-Based Hybrid Scaffolds for Deciphering the Role of Multi-Modal Cues in Cardiac Tissue Engineering. ACS Nano. 2019;13:12525-399.

8. Hussein $\mathrm{KH}$, Abdelhamid HN, Zou X, Woo HM. Ultrasonicated graphene oxide enhances bone and skin wound regeneration. Mater Sci Eng C Mater Biol Appl. 2019;94:484-92.

9. Zheng H, Ji Z, Roy KR, et al. Engineered graphene oxide nanocomposite capable of preventing the evolution of antimicrobial resistance. ACS Nano. 2019;13:11488-99.

10. Shahnawaz Khan M, Abdelhamid HN, Wu H-F. Near infrared (NIR) laser mediated surface activation of graphene oxide nanoflakes for efficient antibacterial, antifungal and wound healing treatment. Colloids Surf B. 2015;127:281-91.

11. Zhao X, Wu K, Lyu H, et al. Porphyrin functionalized $\mathrm{Co}(\mathrm{OH}) 2 / \mathrm{GO}$ nanocomposites as an excellent peroxidase mimic for colorimetric biosensing. Analyst. 2019;144(17):5284-91.

12. Thangamuthu M, Hsieh KY, Kumar PV, Chen GY. Graphene- and graphene oxide-based nanocomposite platforms for electrochemical biosensing applications. Int J Mol Sci. 2019;20(12):2975.

13. Chiticaru EA, Pilan L, Damian CM, Vasile E, Burns JS, Ionita M. Influence of graphene oxide concentration when fabricating an electrochemical biosensor for DNA detection. Biosensors. 2019;9(4):113.

14. Abdelhamid HN, Wu H-F. Multifunctional graphene magnetic nanosheet decorated with chitosan for highly sensitive detection of pathogenic bacteria. J Mater Chem B. 2013;1(32):3950-61.

15. Rauti R, Lozano N, Leon , et al. Graphene oxide nanosheets reshape synaptic function in cultured brain networks. ACS Nano. 2016;10(4):4459-71.

16. Musto M, Rauti $R$, Rodrigues $A F$, et al. 3D organotypic spinal cultures: exploring neuron and neuroglia responses upon prolonged exposure to graphene oxide. Front Syst Neurosci. 2019;13:1.

17. Allen NJ, Barres B. Glia-more than just brain glue. Nature. 2009:457(7230):675-6777.

18. McKenna MC. Substrate competition studies demonstrate oxidative metabolism of glucose, glutamate, glutamine, lactate and 3-hydroxybutyrate in cortical astrocytes from rat brain. Neurochem Res. 2012;37(11):2613-26.

19. Molofsky AV, Deneen B. Astrocyte development: a guide for the perplexed. Glia. 2015;63(8):1320-9.

20. Block ML, Zecca L, Hong JS. Microglia-mediated neurotoxicity: uncovering the molecular mechanisms. Nat Rev Neurosci. 2007;8(1):57-69.

21. Marquez-Ramirez SG, Delgado-Buenrostro NL, Chirino Yl, Iglesias GG, Lopez-Marure R. Titanium dioxide nanoparticles inhibit proliferation and induce morphological changes and apoptosis in glial cells. Toxicology. 2012;302(2-3):146-56.
22. Sruthi S, Mohanan PV. Investigation on cellular interactions of astrocytes with zinc oxide nanoparticles using rat C6 cell lines. Colloids Surf B Biointerfaces. 2015:133:1-11.

23. Sun C, Yin N, Wen R, et al. Silver nanoparticles induced neurotoxicity through oxidative stress in rat cerebral astrocytes is distinct from the effects of silver ions. Neurotoxicology. 2016;52:210-21.

24. Phatnani H, Maniatis T. Astrocytes in neurodegenerative disease. Cold Spring Harb Perspect Biol. 2015;7(6):a020628.

25. Siracusa R, Fusco R, Cuzzocrea S. Astrocytes: role and functions in brain pathologies. Front Pharmacol. 2019;10:1114.

26. Chatterjee S, Sarkar S, Bhattacharya S. Toxic metals and autophagy. Chem Res Toxicol. 2014;27(11):1887-900.

27. Lai SC, Devenish RJ. LC3-associated phagocytosis (LAP): connections with host autophagy. Cells. 2012;1(3):396-408.

28. Ogata T, Oishi Y, Higuchi M, Muraoka I. Fasting-related autophagic response in slow- and fast-twitch skeletal muscle. Biochem Biophys Res Commun. 2010;394(1):136-40.

29. Block ML, Elder $\mathrm{A}$, Auten $\mathrm{RL}$, et al. The outdoor air pollution and brain health workshop. Neurotoxicology. 2012;33(5):972-84.

30. Anguissola S, Garry D, Salvati A, O'Brien PJ, Dawson KA. High content analysis provides mechanistic insights on the pathways of toxicity induced by amine-modified polystyrene nanoparticles. PLOS ONE. 2014;9(9):e108025.

31. Feng X, Chen L, Guo W, et al. Graphene oxide induces p62/SQSTMdependent apoptosis through the impairment of autophagic flux and lysosomal dysfunction in PC12 cells. Acta Biomater. 2018;81:278-92.

32. Stern ST, Adiseshaiah PP, Crist RM. Autophagy and lysosomal dysfunction as emerging mechanisms of nanomaterial toxicity. Part Fibre Toxicol. 2012:9:20.

33. Zhang Y, Ali SF, Dervishi E, et al. Cytotoxicity effects of graphene and single-wall carbon nanotubes in neural phaeochromocytoma-derived PC12 cells. ACS Nano. 2010;4(6):3181-6.

34. Jeong JK, Lee YJ, Jeong SY, Jeong S, Lee GW, Park SY. Autophagic flux induced by graphene oxide has a neuroprotective effect against human prion protein fragments. Int J Nanomedicine. 2017:12:8143-58.

35. Lalwani G, D'Agati M, Khan AM, Sitharaman B. Toxicology of graphenebased nanomaterials. Adv Drug Deliv Rev. 2016;105:109-44.

36. Kimura S, Noda T, Yoshimori T. Dissection of the autophagosome maturation process by a novel reporter protein, tandem fluorescent-tagged LC3. Autophagy. 2007;3(5):452-60.

37. Yang $X$, Yan $X$, Yang D, Zhou J, Song J, Yang D. Rapamycin attenuates mitochondrial injury and renal tubular cell apoptosis in experimental contrast-induced acute kidney injury in rats. Biosci Rep. 2018;38(6).

38. Wallberg F, Tenev T, Meier P. Analysis of Apoptosis and Necroptosis by Fluorescence-Activated Cell Sorting. Cold Spring Harb Protoc. 2016:2016(4):pdb.prot087387.

39. Abdelhamid HN, Wu H-F. Reduced graphene oxide conjugate thymine as a new probe for ultrasensitive and selective fluorometric determination of mercury(II) ions. Microchim Acta. 2015;182:1609-17.

40. Jiang J, Wu S, Lv L, et al. Mitochondrial dysfunction, apoptosis and transcriptomic alterations induced by four strobilurins in zebrafish (Danio rerio) early life stages. Environ Pollut. 2019;253:722-30.

41. Xu X, Mao X, Wang Y, et al. Study on the interaction of graphene oxidesilver nanocomposites with bovine serum albumin and the formation of nanoparticle-protein corona. Int J Biol Macromol. 2018;116:492-501.

42. Casals E, Pfaller T, Duschl A, Oostingh GJ, Puntes V. Time evolution of the nanoparticle protein corona. ACS Nano. 2010;4(7):3623-32.

43. Franqui LS, De Farias MA, Portugal RV, et al. Interaction of graphene oxide with cell culture medium: evaluating the fetal bovine serum protein corona formation towards in vitro nanotoxicity assessment and nanobiointeractions. Mater Sci Eng C Mater Biol Appl. 2019;100:363-77.

44. Chiacchiaretta M, Bramini M, Rocchi A, et al. Graphene oxide upregulates the homeostatic functions of primary astrocytes and modulates astrocyte-to-neuron communication. Nano Lett. 2018;18(9):5827-38.

45. Akhavan O, Ghaderi E, Akhavan A. Size-dependent genotoxicity of graphene nanoplatelets in human stem cells. Biomaterials. 2012;33(32):8017-25

46. Ruiz ON, Fernando KAS, Wang B, et al. Graphene oxide: a nonspecific enhancer of cellular growth. ACS Nano. 2011;5(10):8100-7. 
47. Yp L, QI W, YI Z, et al. Response of microRNAs to in vitro treatment with graphene oxide. ACS Nano. 2014;8:2100-10.

48. Gurunathan S, Kang MH, Jeyaraj M, Kim JH. Differential cytotoxicity of different sizes of graphene oxide nanoparticles in leydig (TM3) and sertoli (TM4) cells. Nanomaterials. 2019;9(2):139.

49. Lammel T, Boisseaux P, Fernández-Cruz ML, Navas JM. Internalization and cytotoxicity of graphene oxide and carboxyl graphene nanoplatelets in the human hepatocellular carcinoma cell line Hep G2. Part Fibre Toxicol. 2013;10:27.

50. $\mathrm{Mu} \mathrm{Q}, \mathrm{Su}$ G, Li L, et al. Size-dependent cell uptake of protein-coated graphene oxide nanosheets. ACS Appl Mater Interfaces. 2012:4(4):2259-66.

51. Xu M, Zhu J, Wang F, et al. Improved in vitro and in vivo biocompatibility of graphene oxide through surface modification: poly(acrylic acid)-functionalization is superior to PEGylation. ACS Nano. 2016;10(3):3267-81.

52. Ou L, Song B, Liang H, et al. Toxicity of graphene-family nanoparticles: a general review of the origins and mechanisms. Part Fibre Toxicol. 2016;13(1):57

53. Saxton RA, Sabatini DM. mTOR signaling in growth, metabolism, and disease. Cell. 2017;169(2):361-71.

54. Fan $L$, Yin S, Zhang E, Hu H. Role of p62 in the regulation of cell death induction. Apoptosis. 2018;23(3-4):187-93.

55. Hou B, Wang G, Gao Q, et al. SQSTM1/p62 loss reverses the inhibitory effect of sunitinib on autophagy independent of AMPK signaling. Sci Rep. 2019:9(1):11087.

56. Mittal S, Sharma PK, Tiwari R, et al. Impaired lysosomal activity mediated autophagic flux disruption by graphite carbon nanofibers induce apoptosis in human lung epithelial cells through oxidative stress and energetic impairment. Part Fibre Toxicol. 2017;14(1):15.

57. Wei M, Fu Z, Wang C, Zheng W, Li S, Le W. Graphene oxide nanocolloids induce autophagy-lysosome dysfunction in mouse embryonic stem cells. J Biomed Nanotechnol. 2019;15(2):340-51.

58. Wan B, Wang ZX, Lv QY, et al. Single-walled carbon nanotubes and graphene oxides induce autophagosome accumulation and lysosome impairment in primarily cultured murine peritoneal macrophages. Toxicol Lett. 2013;221(2):118-27.

59. Heras-Sandoval D, Perez-Rojas JM, Pedraza-Chaverri J. Novel compounds for the modulation of mTOR and autophagy to treat neurodegenerative diseases. Cell Signal. 2019;65:109442.

60. Schmeisser K, Parker JA. Pleiotropic effects of mTOR and autophagy during development and aging. Front Cell Dev Biol. 2019;7:192.
61. Jin P, Wei P, Zhang Y, et al. Autophagy-mediated clearance of ubiquitinated mutant huntingtin by graphene oxide. Nanoscale. 2016;8(44):18740-50

62. Wang B, Zhang J, Chen C, et al. The size of zinc oxide nanoparticles controls its toxicity through impairing autophagic flux in A549 lung epithelial cells. Toxicol Lett. 2018;285:51-9.

63. Kroemer $\mathrm{G}$, Jaattela M. Lysosomes and autophagy in cell death control. Nat Rev Cancer. 2005;5(11):886-97.

64. Saftig P, Klumperman J. Lysosome biogenesis and lysosomal membrane proteins: trafficking meets function. Nat Rev Mol Cell Biol. 2009;10(9):623-35.

65. Manshian BB, Pokhrel S, Madler L, Soenen SJ. The impact of nanoparticledriven lysosomal alkalinization on cellular functionality. J Nanobiotechnology. 2018;16(1):85

66. Guicciardi ME, Leist M, Gores GJ. Lysosomes in cell death. Oncogene. 2004;23(16):2881-900.

67. Nakashima S, Hiraku Y, Tada-Oikawa S, et al. Vacuolar H+-ATPase inhibitor induces apoptosis via lysosomal dysfunction in the human gastric cancer cell line MKN-1. J Biochem. 2003;134(3):359-64.

68. Li Y, Liu Y, Fu Y, et al. The triggering of apoptosis in macrophages by pristine graphene through the MAPK and TGF-beta signaling pathways. Biomaterials. 2012;33(2):402-11.

69. Mc D, Gr B, Yt L, et al. Minimizing oxidation and stable nanoscale dispersion improves the biocompatibility of graphene in the lung. Nano Lett. 2011;11(12):5201-7.

70. Mcllwain DR, Berger T, Mak TW. Caspase functions in cell death and disease. Cold Spring Harb Perspect Biol. 2013;5(4):a008656.

71. Schmitt E, Sané AT, Steyaert A, Cimoli G, Bertrand R. The BCl-xL and Bax-a control points: modulation of apoptosis induced by cancer chemotherapy and relation to TPCK-sensitive protease and caspase activation. Biochem Cell Biol. 1997;75:301-14

72. Stevens M, Oltean S. Modulation of the apoptosis gene Bcl-x function through alternative splicing. Front Genet. 2019;10:804.

73. $X u$ Z, Yang L, Xu S, Zhang Z, Cao Y. The receptor proteins: pivotal roles in selective autophagy. Acta Biochim Biophys Sin. 2015;47(8):571-80.

\section{Publisher's Note}

Springer Nature remains neutral with regard to jurisdictional claims in published maps and institutional affiliations.
Ready to submit your research? Choose BMC and benefit from:

- fast, convenient online submission

- thorough peer review by experienced researchers in your field

- rapid publication on acceptance

- support for research data, including large and complex data types

- gold Open Access which fosters wider collaboration and increased citations

- maximum visibility for your research: over 100M website views per year

At BMC, research is always in progress.

Learn more biomedcentral.com/submissions 